\title{
Summary and Assessment of Metallic Fuel Capabilities in Bison
}

\section{M2MS-18IN0201012}

Milestone report

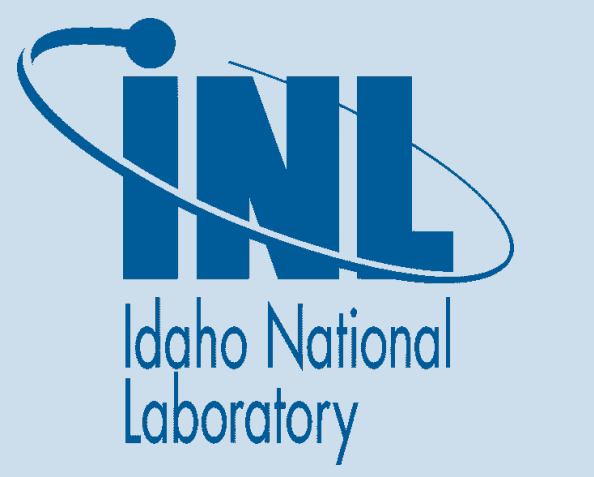
S. R. Novascone
A. Casagranda
P. G. Medvedev
C. Matthews
A. X. Zabriskie 


\section{NOTICE}

This information was prepared as an account of work sponsored by an agency of the U.S. Government. Neither the U.S. Government nor any agency thereof, nor any of their employees, makes any warranty, express or implied, or assumes any legal liability or responsibility for any third party's use, or the results of such use, of any information, apparatus, product, or process disclosed herein, or represents that its use by such third party would not infringe privately owned rights. The views expressed herein are not necessarily those of the U.S. Nuclear Regulatory Commission. 
INL/EXT-18-51399

\section{M2MS-18IN0201012}

\section{Summary and Assessment of Metallic Fuel Capabilities in Bison}

Milestone report

S. R. Novascone
A. Casagranda
P. G. Medvedev C. Matthews

A. X. Zabriskie

September 2018

Idaho National Laboratory

Fuel Modeling and Simulation Department Idaho Falls, ID 83415

Prepared for the U.S. Department of Energy Office of Nuclear Energy

Under U.S. Department of Energy-Idaho Operations Office Contract DE-AC07-99ID13727 


\begin{abstract}
The work described in this report was performed under funding from the Nuclear Energy Advanced Modeling and Simulation (NEAMS) program. This report is issued in satisfaction of the level 2 milestone M2MS-18IN0201012 on Release Bison with Initial Metallic Fuel Performance Capability.

Metallic fuel development began in Bison a few years after light water reactor development began $(\sim 2009)$. The initial development was funded by the Advanced Fuels Campaign. With recent interest from industry, the Nuclear Regulatory Commission, and the Versatile Test Reactor program, the Nuclear Energy Modeling Simulation Program has increased funding for metallic fuel development and validation in FY18. The material models with the most mature development are binary uranium-zirconium and ternary uranium-plutonium-zirconium alloys for fuel and HT9 for cladding. The first material models were incorporated from open literature sources, which include mechanical and thermal material properties that are functions of temperature, porosity, and zirconium concentration, swelling, fission gas release, zirconium diffusion, creep, and sodium coolant channel boundary conditions. These material models have been utilized to simulate ERB-II fuel pins and the results compared to measurements. The EBR-II experiment measurements mostly consist of cladding strain and zirconium redistribution. As such, comparisons to EBR-II measurements are currently limited to these two figures of merit. Simulations and comparisons to experiment measurements have also been done for transient testing of EBRII fuel pins in TREAT, which included temperature measurements. Preliminary comparisons between Bison calculations and experiment measurements are favorable. These comparisons have also highlighted the importance of the fuel swelling and fission gas release models on cladding strain. Also, Bison metallic fuel simulations are currently being run in support of ATR experiments and VTR exploratory design calculations. Further development and evaluation of individual material models and fuel system models are planned for FY19.
\end{abstract}




\section{Contents}

1 Introduction 1

2 Background 2

2.1 History of Metallic Fuel . . . . . . . . . . . . . . . . . . . . . 2

3 Bison Metallic Fuel Capability and Development Status 4

3.1 Simulation Description - PDEs, Geometry, and Boundary Conditions . . . . . . 4

3.2 High-Level Material Model Description . . . . . . . . . . . . . . 6

3.3 Metallic Fuel Specific Material Models . . . . . . . . . . . . . . . . . 7

3.3.1 Fuel Elasticity Model: UPuZrElasticityTensor . . . . . . . . . . . . . . 7

3.3.2 Fuel Creep Model: UPuZrCreepUpdate . . . . . . . . . . . . . . . . 8

3.3.3 Volumetric Swelling Model: UPuZrVolumetricSwellingEigenstrain . . 9

3.3.4 Fuel Thermal Model: ThermalUPuZrTernary . . . . . . . . . . . . . . 10

3.3.5 Fission Gas Release Model: FgrUPuZr . . . . . . . . . . . . . . . . . 11

3.3.6 Zirconium Diffusion Models: ZrDiffusivityUPuZr and PhaseUPuZr . . 12

3.3.7 Cladding Creep Model: HT9CreepUpdate . . . . . . . . . . . . . . . . 12

3.3.8 Cladding Thermal Model: ThermalHT9 . . . . . . . . . . . . . . . . 13

3.4 Coolant Channel Models . . . . . . . . . . . . . . . . . . . . . . . . . 13

3.5 Material Models Currently in Development . . . . . . . . . . . . . . . . . . 14

3.6 Comparison to Experimental Data for Individual Material Models . . . . . . . 15

4 Comparing EBR-II measurements to Bison Calculations 16

4.1 Description of X447 and X441 Experiments . . . . . . . . . . . . . . 17

4.2 Results - X447 Binary Fuel . . . . . . . . . . . . . . . . . . . . . . . . 18

4.3 Results - X441 Ternary Fuel . . . . . . . . . . . . . . . . . . . . 21

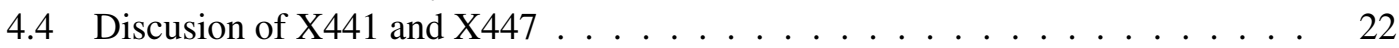

4.5 Comparison to the TREAT M7 Experiment $\ldots \ldots \ldots . \ldots . \ldots 22$

5 Calculations in Support of Experiment Design 25

5.1 ATR Experiment Design Calculations _ . . . . . . . . . . . . . . . . 25

5.2 Use of Bison for Modeling Deformation of Slotted Metallic Fuel . . . . . . . 29

5.3 VTR Exploratory Calculations . . . . . . . . . . . . . . . . 33

6 Future Work 36

6.1 Additional Assessment Cases . . . . . . . . . . . . . . . . . . . . . . . 36

6.1.1 Effect of Plenum/Fuel Volume Ratio on Cladding Strain . . . . . . . 36

6.1.2 Effect of Fuel Smear Density on Cladding Strain . . . . . . . . . . 36 
6.1.3 Effect of Zr Content on Cladding Strain . . . . . . . . . . . . . . . 37

6.1.4 Effect of Cladding Material (D9/HT9) on Cladding Strain . . . . . . 37

$\begin{array}{llc}7 & \text { Conclusions } & 38\end{array}$

$\begin{array}{ll}\text { Acknowledgments } & 39\end{array}$

$\begin{array}{ll}\text { Bibliography } & \mathbf{4 0}\end{array}$ 


\section{Introduction}

Bison [1] is a modern finite-element based, multidimensional fuel performance code developed at Idaho National Laboratory (INL). Bison has been adopted as the fuel performance tool of choice for either model development or application by multiple DOE NE programs (NEAMS and CASL being the primary examples). Bison has also seen growing acceptance by industry. Recent verification and validation work has focused on Light Water Reactor (LWR) fuel in normal operating conditions as well as accident scenarios [1,2]. Here, we describe material models in Bison that are applicable to metallic fuel and show calculations with comparisons to measurements from EBR-II data. 


\section{Background}

\subsection{History of Metallic Fuel}

The Experimental Breeder Reactor (EBR) program operated for approximately 30 years (19641994) and accomplished several important objectives related to sodium cooled fast reactors and metallic fuels [3-6]. The construction of EBR-II began in 1958 and was completed when the reactor started operation in 1964. The initial operating power level was $30 \mathrm{MWt}$ which gradually increased over time to the design power of $62.5 \mathrm{MWt}$. The reactor maintained a fairly high capacity factor of $70 \%$ even though it was essentially an experimental facility.

The first objective of EBR-II was to demonstrate that a closed fuel cycle was possible. This meant that the reactor would generate power while breeding fissionable plutonium from U-238. In addition, the fuel would be reprocessed (i.e. separating fissionable material from fission products), refabricated (i.e., remelted and cast into fuel slugs) and reinserted into the reactor for additional power production. All of these processes were performed on-site thus eliminating the need for transportation of radioactive materials off-site or requiring fresh fuel to be delivered. In addition, since the reprocessing of metallic fuel is not $100 \%$ efficient, the residual fission products make the reprocessed fuel very radioactive thus requiring all of the fuel recycling steps to be performed remotely and increasing proliferation resistance. This goal was achieved in 1969 at which point $\sim 35,000$ fuel pins had gone through these steps successfully.

Following the closed fuel cycle demonstration, EBR-II was used for several years as the main research and development facility for fast reactor fuels and materials. Over this time the metallic fuel compostion and design as well as the cladding materials and geometry were varied in order to achieve higher burnups without cladding failures. Eventually, burnups of $\sim 20 \%$ were reached in EBR-II using a U-Pu-Zr fuel combined with HT9 cladding. Other unique features of the EBR-II reactor included the use of sodium as the coolant and the pool-type configuration of the primary system. Although sodium reacts with water, the high thermal conductivity, high heat capacity, compatibility with stainless steel structural materials and good neutronics properties for a fast reactor are significant advantages. The EBR-II operational experience showed that sodium coolant could be used safely and that leaks can be contained. The pool-type configuration simplified the primary system allowing operation at atmospheric pressure and eliminating the need to deal with pressure boundary design limitations as in a loop type system.

Lastly, in the final years of EBR-II operation, the reactor was utilized to establish the feasibility of the Integral Fast Reactor (IFR) concept. The IFR promoted efficient usage of the world's reserves of uranium and required that the fuel cycle use plutonium generated through breeding of U-238. The U-Pu-Zr fuel system used in EBR-II was ideally suited to fill this requirement. 
Also, to demonstrate the commercial viability of the IFR design, experiments were performed to highlight the inherent safety of metallic fuels. In 1986 both a loss of flow and a loss of heat sink accident were conducted at EBR-II. During both accidents no operator intervention was required and the reactor passively shut down.

Measurements from the EBR-II tests are readily available for review. As such, this data is used to compare and evaluate Bison calculation results. 


\section{Bison Metallic Fuel Capability and Development Status}

Metallic fuel development began in Bison a few years after light water reactor development began ( 2009), so some metallic fuel simulation capability has existed for quite some time. The first material models were incorporated from open literature sources, which included swelling, fission gas release, zirconium diffusion, and creep. The way material model development typically works in Bison is to create a $\mathrm{C}++$ class that represents the material model along with a corresponding regression test that evaluates the model. For example, the regression test for a creep model that is a function of temperature and stress would prescribe temperature and stress by enforcing corresponding boundary conditions, then recording the creep strain. This calculation is checked via paper and pencil or excel "hand calculations" to determine if calculations from the new material class are as expected. The solution to this regression test is saved and checked before other merge requests are approved to ensure that the "hand-checked" solution does not change with subsequent changes to Bison. After the individual material models and regression tests were added to Bison, we started the process of combining them into a single input file that represented a generic EBR-II fuel pin.

The following sections contain high-level, generic descriptions of the equations and material models available in Bison for simulating metallic fuel followed by specific descriptions of the material models used in the simulation results presented here. The last section contains a highlevel description of material models under development.

\subsection{Simulation Description - PDEs, Geometry, and Boundary Conditions}

The partial differential equations are:

$$
\begin{aligned}
\rho C \frac{\partial T}{\partial t}-\nabla \cdot k \nabla T-q & =0 \\
\frac{\partial z}{\partial t}-\nabla \cdot D \nabla z-\nabla \cdot S \nabla T & =0 \\
\nabla \cdot \boldsymbol{\sigma} & =0
\end{aligned}
$$

where $t$ is time, $\rho$ is density, $C$ is specific heat capacity, $k$ is thermal conductivity, $T$ is temperature, $q$ is the heat source term, $z$ is the concentration of zirconium in at. $\%, D$ and $S$ are the 
Fickian and Soret diffusion coefficients respectively, and $\boldsymbol{\sigma}$ is the stress tensor. The symbol $\nabla$ is the del operator and changes form depending on the coordinate system. These equations are solved implicitly (fully coupled to each other), using the finite element formulation.

Since EBR-II fuel is cylindrical and enclosed in hollow cylindrical cladding, Bison's RZ cylindrical symmetry feature is utilized. This type of symmetry means that from the fuel pin center, radial and azimuthal symmetry is assumed. All models discussed here use this geometric configuration. Figure 3.1 shows a simplified image of the fuel, which is a scaled version of the actual geometry for presentation. The actual geometry is roughly $1 / 3 \mathrm{~m}$ fuel length, $2 \mathrm{~mm}$ fuel radius, $1 / 4 \mathrm{~m}$ plenum height above the fuel, $380 \mu \mathrm{m}$ cladding thickness, and a $350 \mu \mathrm{m}$ gap. This geometry is meshed with four or eight node elements.

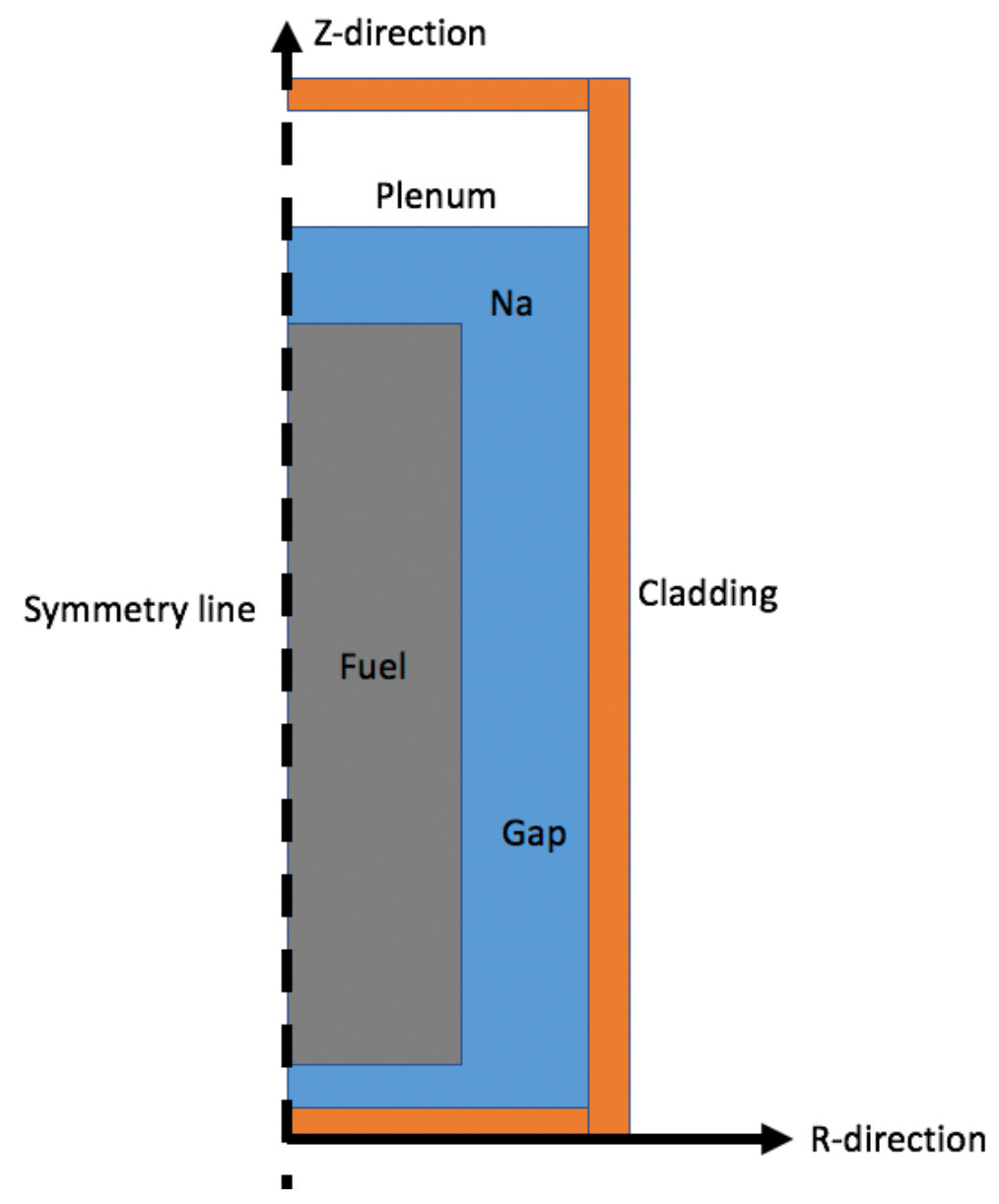

Figure 3.1: Sketch of EBR-II metallic fuel pin geometry, with RZ-symmetry scaled for presentation.

To solve Equations 3.1, 3.2, and 3.3, boundary conditions must be applied with consideration for RZ cylindrical symmetry. Along the symmetry line, zero flux boundary conditions for the 
temperature and zirconium variables are applied, along with zero displacement in the radial direction. Boundary conditions that represent plenum and coolant pressure are applied to the inside and outside of the cladding, who's values correspond to EBR-II experiment documentation. A thermal flux boundary condition applied to the outside of the cladding that accounts for sodium fluid properties and mass flow rate is also applied. The equation for zirconium diffusion, 3.2 , is only solved in the part of the finite element mesh that represents the fuel, and the only boundary condition applied to the zirconium variable is zero flux on all fuel surfaces. Finally, the linear heat rate recorded in the EBR-II data is used calculate a volumetric heat source term, $q$ in Equation 3.1, and applied to the mesh that represents the fuel.

\subsection{High-Level Material Model Description}

Starting with the fuel, the mechanical performance is governed by a model that represents the elastic moduli (Poisson's ratio and Young's modulus) as functions of temperature, porosity, and zirconium and plutonium content. A creep model that is a function of fission rate, temperature, and porosity is also used.

Eigen strains (stress free strains) are modeled by constant thermal expansion along with gaseous and solid fission product swelling models. The solid swelling model is a straight-forward model directly proportional to fission rate. The gaseous swelling model comes from a force balance applied to a bubble with the metallic fuel and generates porosity at all material points (quadrature points) in the domain.

Moving on to fuel thermal behavior, the thermal conductivity model in the fuel is a function of temperature, porosity, and zirconium and plutonium content. The heat capacity models are functions of temperature and alloy phase.

The fission gas model is simply based on fission rate for gas generation and the fission gas released is governed by the value of porosity; when the value of porosity $=0.25,80 \%$ of the fission gas produced so far is released and, moving forward, all the subsequent fission gas produced is immediately released [7]. The porosity is generated by the gas swelling model.

Cladding mechanical response is governed by constant elastic moduli, thermal and irradiation creep, and thermal expansion. Thermal conductivity and heat capacity models are functions of temperature.

The redistribution of zirconium is governed by Fickian and Soret diffusion. Zirconium content has an important effect on material properties and fission rate. The zirconium kernels and supporting material properties, such as diffusion coefficients, are in the process of being updated, so we have only one comparison to show in this report. 


\subsection{Metallic Fuel Specific Material Models}

The following is a list of $\mathrm{C}++$ classes that define the material models used in the results presented in this document.

- UPuZrElasticityTensor

- UPuZrCreepUpdate

- UPuZrVolumetricEigenstrain

- ThermalUPuZr

- FgrUPuZr

- ZrDiffusivityUPuZr

- PhaseUPuZr

- HT9CreepUpdate

- ThermalHT9

\subsubsection{Fuel Elasticity Model: UPuZrElasticityTensor}

Due to the redistribution of zirconium in the fuel, and the need to model both $\mathrm{U}-\mathrm{Zr}$ and $\mathrm{U}-\mathrm{Pu}-\mathrm{Zr}$ fuel, correlations included in 'UPuZrElasticityTensor' must be applicable to any concentration of plutonium or zirconium. Unfortunately, the available models for the elastic properties of U$\mathrm{Pu}-\mathrm{Zr}$ alloys are generally incomplete. Regardless, some correlations can be made given the sparse data, as described in [8].

The correlation for Young's modulus can be derived using data from $\mathrm{U}-11 \mathrm{Pu}-6.3 \mathrm{Zr}$ cast fuel pins as:

$$
E=E_{u}\left(1-\beta_{E} P\right)\left(\frac{1+0.17 W_{Z r}}{1+1.34 W_{Z r}}-W_{P u}\right)\left(1-1.06\left[\frac{T-588}{T_{m u}}\right]\right)
$$

where $E_{u}=1.6 \times 10^{5} \mathrm{MPa}$ is the Young's modulus for pure $\mathrm{U}$ at the reference temperature of $588 \mathrm{~K}, P$ is the fractional porosity, $W_{Z r}$ is the zirconium weight fraction, $W_{P u}$ is the plutonium weight fraction, $T$ is the temperature in $\mathrm{K}$, and $T_{m u}=1405 \mathrm{~K}$ is the melting temperature of pure uranium. $\beta_{E}$ is the Young's modulus degradation factor due to porosity, and is typically 1.2.

The correlation for Poisson's ratio can be derived from the U-Zr correlation as:

$$
v=v_{u}\left(1-\beta_{p} P\right)\left(\frac{1+3.4 W_{Z r}}{1+1.9 W_{Z r}}\right)\left(1+1.2\left[\frac{T-588}{T_{m u}}\right]\right)
$$

where $v_{u}=0.24$ is the Poisson's ratio of pure $\mathrm{U}$ at the reference temperature of $588 \mathrm{~K} . \beta_{p}$ is the Poissons' ratio degradation factor due to porosity, and is typically 0.8 . 


\subsubsection{Fuel Creep Model: UPuZrCreepUpdate}

'UPuZrCreepUpdate' is used to model the thermal and irradiation creep behavior of U-Pu-Zr fast reactor fuel. If 'porosity' and 'porosity_material' are both defined an error will result. The user has the choice of not supplying any porosity, supplying a variable for porosity, or coupling to a material that calculates the porosity.

A model for combined secondary thermal creep and irradiation creep for $\mathrm{U}-\mathrm{Pu}-\mathrm{Zr}$ fast reactor fuel is available, with the creep rate modeled as a function of time, fuel porosity, effective stress, and fission rate. The constitutive relation is taken from [9] and is given as

$$
\begin{aligned}
\dot{\varepsilon} & =A_{1}\left(1+7.9 p+470 p^{2}\right) \exp \left(\frac{-Q_{1}}{R T}\right) \sigma \\
& +A_{2}\left(1-p^{0.67}\right)^{-4.5} \exp \left(\frac{-Q_{2}}{R T}\right) \sigma^{4.5} \\
& +A_{3} \dot{F} \sigma
\end{aligned}
$$

where $\dot{\varepsilon}$ is the creep rate (1/s), $\sigma$ is the effective (Mises) stress (MPa), $T$ is the temperature (K), $p$ is the porosity, $\dot{F}$ is the volumetric fission rate (fissions $/ \mathrm{cm}^{3}$-s), $Q_{i}$ are the activation energies (cal/mol), $R$ is the universial gas constant $(1.987 \mathrm{cal} / \mathrm{mol}-\mathrm{K})$ and $A_{1-3}$ are material constants given as $A_{1}=5 \times 10^{3}, A_{2}=6$, and $A_{3}=7.7 \times 10^{-23}$.

The first term in 3.6 represents diffusional thermal creep and is applicable to low stress and low temperature conditions. The second term represents thermal dislocation or power-law creep and is applicable to high stress and high temperature conditions. The third term represents the irradiation creep as it depends upon the fission rate. The activation energies for the thermal creep terms $\left(Q_{1}\right.$ and $\left.Q_{2}\right)$ are given as $Q_{1}=Q_{2}=52000 \mathrm{cal} / \mathrm{mol}$.

These $\mathrm{U}$ and $\mathrm{Pu}$ alloys have a phase change temperature of $923.15 \mathrm{~K}$. Above this temperature, the creep rate equation changes to

$$
\dot{\varepsilon}=A_{4}\left(1-p^{0.67}\right)^{-3} \exp \left(\frac{-Q_{3}}{R T}\right) \sigma^{3}+A_{3} \dot{F} \sigma
$$

where $A_{4}$ is $8.0 \times 10^{-2}$ and $Q_{3}$ is $28500 \mathrm{cal} / \mathrm{mol}$.

The material model 'ThermalUPuZr' calculates the thermal conductivity and heat capacity of $\mathrm{U}-x \mathrm{Pu}-y \mathrm{Zr}$, where $x$ and $y$ refers to the weight fraction of $\mathrm{Pu}$ and $\mathrm{Zr}$ respectively. The material model accepts either constant values for the weight fractions $x$ and $y$, or can be coupled to molar fractions that in turn can be used by other kernels or material models. If atom fractions are 
provided, 'ThermalUPuZr' converts them into weight fractions:

$$
\begin{aligned}
& w_{U}=(1-x-y) A_{U} / M_{A}, \\
& w_{P u}=x A_{P u} / M_{A}, \\
& w_{Z r}=y A_{Z r} / M_{A}, \\
& M_{A}=(1-x-y) A_{U}+x A_{P u}+y A_{Z r},
\end{aligned}
$$

where $A$ is the atomic weight of each element in $\mathrm{kg} / \mathrm{mol}$, and $M_{A}$ is the average atomic mass of the fuel mixture in $\mathrm{kg} / \mathrm{mol}$.

\subsubsection{Volumetric Swelling Model: UPuZrVolumetricSwellingEigenstrain}

This model, 'UPuZrVolumetricSwellingEigenstrain', computes a volumetric strain to account for solid and gaseous swelling in U-Pu-Zr metallic fuel systems. The solid swelling and gaseous swelling are optionally saved as a material property, named 'solid swelling' and 'gas swelling', respectively. Also, porosity (as-fabricated + gas swelling porosity) is available as a material property.

The derivation for the mechanistic fuel swelling model for U-Pu-Zr systems used here was originally presented in [10]. First, it is assumed that the fission gas generated in the fuel instantly forms fission gas bubbles having a diameter of $5 \mu \mathrm{m}$. The mechanical force balance on an equilibrium bubble can be expressed as follows [11]:

$$
p=\frac{2 \gamma}{r_{b}}-\sigma_{h}+\sigma_{c r}
$$

where $p$ is the pressure of the fission gas in a bubble, $\gamma$ is the surface tension of the fuel, $r_{b}$ is the fission gas bubble size, $\sigma_{h}$ is the hydrostatic stress in the fuel, and $\sigma_{c r}$ is the creep strength stress of the fuel. The gas pressure in the bubble is governed by the ideal gas law:

$$
p V=\vee R T
$$

where $p, V, v, R, T$, are the pressure, volume, amount, universal gas constant, and temperature of the fission gas, respectively. By rearranging the ideal gas law to calculate the volume of the fission gas and substituting the mechanical force balance equation, the following is obtained for the volume of the fission gas:

$$
V=\frac{\nu R T}{\frac{2 \gamma}{r_{b}}-\sigma_{h}+\sigma_{c r}} .
$$

Substituting $\mathrm{r}_{b}=0.5 \mu \mathrm{m}, \gamma=0.8 \mathrm{~N} / \mathrm{m}$ [12], and $\sigma_{c r}=6.9 \times 10^{6} \mathrm{~Pa}$, from [13] for pure U, the fuel swelling due to fission gas is obtained: 


$$
\left(\frac{\Delta V}{V_{0}}\right)_{g}=\frac{3.59 \times 10^{-24} F T}{1.01 \times 10^{7}-\sigma_{h}}
$$

where $T$ is the temperature in Kelvin, $F$ is in fission $/ \mathrm{m}^{3}$, and $\sigma_{h}$ is in Pa. The porosity of metallic fuel, also calculated in VSwellingUPuZr, is obtained from [10] and is given by

$$
p=\frac{\left(\frac{\Delta V}{V_{o}}\right)_{g}}{\left(\frac{\Delta V}{V_{o}}\right)_{g}+1}
$$

where $V$ is the current volume and $V_{o}$ is the orginal volume.

Swelling due to solid fission products is assumed to be $1.5 \%$ per $1 \%$ burnup as suggested by [14]:

$$
\left(\frac{\Delta V}{V_{0}}\right)_{s}=4.16 \times 10^{-29} \mathrm{~F}
$$

where $F$ is the fission rate density in fissions $/ \mathrm{m}^{3}, V$ is the current volume, and $V_{o}$ is the original volume.

Following [15], the total volumetric swelling is the summation of contributions from gaseous and solid swelling:

$$
\left(\frac{\Delta V}{V_{0}}\right)_{\text {total }}=\left(\frac{\Delta V}{V_{0}}\right)_{g}+\left(\frac{\Delta V}{V_{0}}\right)_{s}
$$

There are several different models available for calculation of thermal conductivity and heat capacity for unirradiated fuel as described in the following sections.

\subsubsection{Fuel Thermal Model: ThermalUPuZrTernary}

Recent work has been applied to extend Kim's model to more data, resulting in new coefficients [16]. These coefficients are also available as a separate model, designated 'LANL':

$$
\begin{aligned}
k_{U}= & 21.76+1.665 \times 10^{-2} T+5.167 \times 10^{-6} T^{2}, \\
k_{P u}= & -8.162+4.841 \times 10^{-2} T-1.614 \times 10^{-5} T^{2}, \\
k_{c, U-Z r}= & -97.0+177.9 f_{Z r}-95.94 f_{Z r}^{2}+8.351 \times 10^{-3} T \\
& +2.931 \times 10^{-5} T^{2}-5.694 \times 10^{-3} f_{Z r} T \\
k_{c, P u}= & -135.8-29.89 w_{P u}+351.9 w_{P u}^{2}+0.3571-1.186 \times 10^{-4} T^{2}-0.961 w_{P u} T
\end{aligned}
$$


Although only slightly different, when the updated coefficients are plugged into the remainder of the ternary model, the calculation of thermal conductivity results in a standard deviation of less than $1 \mathrm{~W} / \mathrm{m}-\mathrm{K}$.

When taking into account irradiation effects through the introduction and growth of porosity, the thermal conductivity becomes,

$$
k=f_{p} k_{o}
$$

where

$$
f_{p}=\frac{1-p}{1+\beta_{p} p}
$$

The porosity $p$ is calculated by [UPuZrVolumetricSwellingEigenstrain] (/UPuZrVolumetricSwellingEigenstrain.md) (or the Solid Mechanics version, [VSwellingUPuZr] (/VSwellingUPuZr.md)) and passed to 'ThermalUPuZr' as an auxkernel. The porosity constant $\beta_{p}$ is typically taken as 2.5 for conservatism as recommended by [17].

The correlation for heat capacity from Savage is split into the low temperature $\alpha+\delta$ region, and the high temperature $\gamma$ region:

$$
\begin{gathered}
C_{p}^{\alpha+\delta}(T)=6.36+0.00636 \cdot T, \text { for } 25^{\circ} \mathrm{C}<T<600^{\circ} \mathrm{C} \\
C_{p}^{\gamma}(T)=3.79+0.00623 \cdot T, \text { for } T>650^{\circ} \mathrm{C}
\end{gathered}
$$

where $T$ is temperature in ${ }^{\circ} \mathrm{C}$, and $C_{p}$ is given in cal $/ \mathrm{mol}-{ }^{\circ} \mathrm{C}$. A simple linear interpolation is used for the $\beta+\gamma$ region:

$$
C_{p}^{\beta+\gamma}(T)=\left(\frac{C_{p}^{\gamma}\left(T_{\text {high }}\right)-C_{p}^{\alpha+\delta}\left(T_{\text {low }}\right)}{T_{\text {high }}-T_{\text {low }}}\right)\left(T-T_{\text {low }}\right)+C_{p}^{\alpha+\delta}\left(T_{\text {low }}\right),
$$

where $T_{l o w}$ and $T_{\text {high }}$ are the transition temperature $600{ }^{\circ} \mathrm{C}$ and $650{ }^{\circ} \mathrm{C}$ respectively.

Lastly, $C_{p}$ is converted from cal $/\left(\mathrm{mol}-{ }^{\circ} \mathrm{C}\right)$ to $\mathrm{J} /(\mathrm{kg}-\mathrm{K})$ by multipling $3.19,3.20$, or 3.21 by 4.184 $(\mathrm{J} / \mathrm{cal})$ and $0.205(\mathrm{~kg} / \mathrm{mol})$. It is important to note that the $\mathrm{kg}$ to mol conversion is kept constant, as it applies directly to the data captured by Savage. Changing the conversion factor will result in a dependency on the concentrations of $\mathrm{Pu}$ and $\mathrm{Zr}$ in the fuel that is not based on data, as is the case with the Karahan model described above.

\subsubsection{Fission Gas Release Model: FgrUPuZr}

'FgrUPuZr' is a fission gas release model for UPuZr metallic fuel. The amount of fission gas generated per unit volume of fuel is given by

$$
v=\frac{0.26 F}{N_{A}}
$$


where $\mathrm{F}$ is the fission density, 0.26 is the fission yield of gas atoms (can be provided by the user), and $\mathrm{N}_{A}$ is Avogadro's number. According to [11] when swelling due to fission gas bubbles reaches $33 \%$, the fission gas bubbles interconnect, and $80 \%$ of the fission gas is released.

Interconnection of the fission gas bubbles transforms closed porosity into the open porosity that facilitates instant release of any consequently generated fission gas. Thus, the fission gas induced swelling is terminated, once the interconnection threshold is reached. In the code, porosity is calculated and is monitored in 'FgrUPuZr" (read-in as a material property from [VSwellingUPuZr](/Materials/VSwellingUPuZr.md)).

When the porosity equals 0.24812 (corresponding to a gaseous swelling of $33 \%$ ), $80 \%$ of the fission gas is released after which, all of the fission gas generated is released.

\subsubsection{Zirconium Diffusion Models: ZrDiffusivityUPuZr and PhaseUPuZr}

PhaseUPuZr - material that tracks phase amount $(\alpha, \beta, \gamma, \delta$, and $\zeta)$ based on local temperature and $\mathrm{Pu}$ and $\mathrm{Zr}$ concentration

Zirconium redistribution in $\mathrm{U}-\mathrm{Zr}$ and $\mathrm{U}-\mathrm{Pu}-\mathrm{Zr}$ based fuels impacts both fuel mechanical and thermal performance.

Using the phase fractions calculated in PhaseUPuZr, ZrDiffusivityUPuZr calculates the Fickian and Soret diffusion coefficients using

$$
\begin{aligned}
D(x, T)= & D_{\pi}(x, T) \\
S(x, T)= & D_{\pi}(x, T)\left(\frac{x\left(1-x_{\mathrm{Pu}}-x\right)}{1-x_{\mathrm{Pu}}}\right) \frac{Q_{\pi}^{\star}}{R T^{2}} \\
S(x, T)= & f_{\beta} D_{\beta}\left(X_{\beta}(T), T\right)\left(\frac{X_{\beta}(T)\left(1-x_{\mathrm{Pu}}-X_{\beta}(T)\right)}{1-x_{\mathrm{Pu}}}\right)\left(\frac{\Delta H_{\beta}+Q_{\beta}^{*}}{R T^{2}}\right) \\
& +\left(1-f_{\beta}\right) D_{\gamma}\left(X_{\gamma}(T), T\right)\left(\frac{X_{\gamma}(T)\left(1-x_{\mathrm{Pu}}-X_{\gamma}(T)\right)}{1-x_{\mathrm{Pu}}}\right)\left(\frac{\Delta H_{\gamma}+Q_{\gamma}^{*}}{R T^{2}}\right)
\end{aligned}
$$

The artificial two-phase diffusivity parameter $p$ is used to set the diffusivity in the two-phase regions, and is typically set to $p=0.2$. A scalar factor $D_{0, s c a l a r}$ is also included to tune the diffusivities within each phase. It should be noted that $D_{0, \text { scalar }}$ is multiplied against all diffusivity values, including the Soret calculation, except for the artificial two-phase regions. In these regions, the only scalar utilized is the $p$ values.

\subsubsection{Cladding Creep Model: HT9CreepUpdate}

Thermal and irradiation creep models and material properties from [8] are used for the HT9 model, 'HT9CreepUpdate'. The first two terms of the following equation are for secondary 
creep and the last term represents the irradiation creep contribution [18].

$$
\dot{\varepsilon}_{c r}=C_{5} \exp \left(-\frac{Q_{4}}{R T}\right) \bar{\sigma}^{2}+C_{6} \exp \left(-\frac{Q_{5}}{R T}\right) \bar{\sigma}^{5}+\left[B+A \exp \left(-\frac{Q}{R T}\right)\right] \phi \bar{\sigma}^{1.3}
$$

where $\mathrm{T}$ is the Temperature (K), $\sigma$ is the effective stress (MPa), $\phi$ is the neutron flux $\left(n / \mathrm{cm}^{2}-s\right)$, and $\dot{\varepsilon}_{c r}$ is the effective thermal and irradiation creep strain rate $(1 / s)$. The following are creep coefficients and activation energies for Equation 3.24:

Table 3.1: Parameters used in the HT9 Creep Model

\begin{tabular}{|c|c|}
\hline Model Expression & Parameter Value \\
\hline$A$ & $2.59 \times 10^{14}$ \\
\hline$B$ & $1.83 \times 10^{-4}$ \\
\hline$C_{5}$ & $1.17 \times 10^{9}$ \\
\hline$C_{6}$ & $8.33 \times 10^{9}$ \\
\hline$Q$ & $73000(\mathrm{Cal} / \mathrm{mol})$ \\
\hline$Q_{4}$ & $83142(\mathrm{Cal} / \mathrm{mol})$ \\
\hline$Q_{5}$ & $108276(\mathrm{Cal} / \mathrm{mol})$ \\
\hline$R$ & $1.987(\mathrm{Cal} / \mathrm{K}-\mathrm{mol})$ \\
\hline
\end{tabular}

\subsubsection{Cladding Thermal Model: ThermalHT9}

Thermal conductivity $\mathrm{k}(\mathrm{W} / \mathrm{m}-\mathrm{K})$ of HT9 is from [19]:

$$
\begin{gathered}
k=17.622+2.42 \times 10^{-2} T-1.696 \times 10^{-5} T^{2}, \quad T<1030 \mathrm{~K} \\
k=12.027+1.218 \times 10^{-2} T, \quad T \geq 1030 \mathrm{~K}
\end{gathered}
$$

Specific heat $C_{p}(\mathrm{~J} / \mathrm{kg}-\mathrm{K})$ of HT9 is from [20]:

$$
\begin{gathered}
C_{p}=\frac{(T-500)}{6}+500, \quad T<800 \mathrm{~K} \\
C_{p}=\frac{3(T-800)}{5}+550, \quad T \geq 800 \mathrm{~K}
\end{gathered}
$$

\subsection{Coolant Channel Models}

Two additional sodium heat transfer correlations have been added to the Coolant Channel class; the modified Schad correlation for triangular subchannels is still available. The Lyon's Law 
correlation [21] and Seban and Shimazaki correlation [22] both address sodium heat transfer with a rod inside a tube.

The Lyon's Law correlation is generally used for heat transfer from a rod to flow within a surrounding circular tube for liquid metals

$$
N u=7.0+0.025 P e^{0.8} \text { with } P e=\max (\operatorname{RePr}, 200)
$$

applicable for $\operatorname{Pr} \leq 1$ and $4000 \leq R e \leq 3240000$.

The Seban and Shimazaki correlation is specific to liquid sodium heat transfer from a rod to fluid within a surrounding circular tube with constant rod wall temperature

$$
N u=5.0+0.025 P e^{0.8}
$$

and is applicable for $40 \leq P e \leq 1150,0.0057 \leq P r \leq 0.0075$, and $5850 \leq \operatorname{Re} \leq 178000$.

\subsection{Material Models Currently in Development}

The following is a list of $\mathrm{C}++$ classes that are available in Bison, but are still under development.

- UPuZrFissionRate - a material that modifies the fission rate based on the local (quadrature point) value of $\mathrm{Zr}$ and $\mathrm{Pu}$ concentration

- UPuZrBurnup - burnup calculation based on initial values for initial molar fractions of $\mathrm{Pu}$ and $\mathrm{Zr}$ and the atomics weights of $\mathrm{U}, \mathrm{Pu}$, and $\mathrm{Zr}$.

- UPuZRPhaseLookup - Returns U-Pu-Zr phase fractions, equilibrium concentrations, and multi-phase contributions given temperature and composition using a lookup table

- UPuZrAnisotropicSwellingEigenstrain - an eigen strain model that accounts for the large, radially biased fuel expansion observed in experiment

- ThermalExpansionUPuZr - thermal expansion based on local temperature and $\mathrm{Pu}$ and $\mathrm{Zr}$ concentrations

- SS316ThermalExpansionEigenstrain - an ASME, temperature dependent thermal expansion coefficient

- SS316ElasticityTensor - temperature dependent elastic modulus

- SS316CreepUpdate - thermal and irradiation creep model for annealed 316

- NuclearSystemsMaterialsHandbookSS316CreepUpdate - thermal and irradiation creep model $20 \%$ cold worked 316 . 


\subsection{Comparison to Experimental Data for Individual Material Models}

In order to evaluate the accuracy of the thermal conductivity models described in the previous sections a comparison to available experimental measurements of thermal conductivity for metallic fuels is being compiled. Thus far, data for the $\mathrm{U}-\mathrm{xZr}$ system was found and is compared with the LANL model implemented in Bison in Figure 3.2.

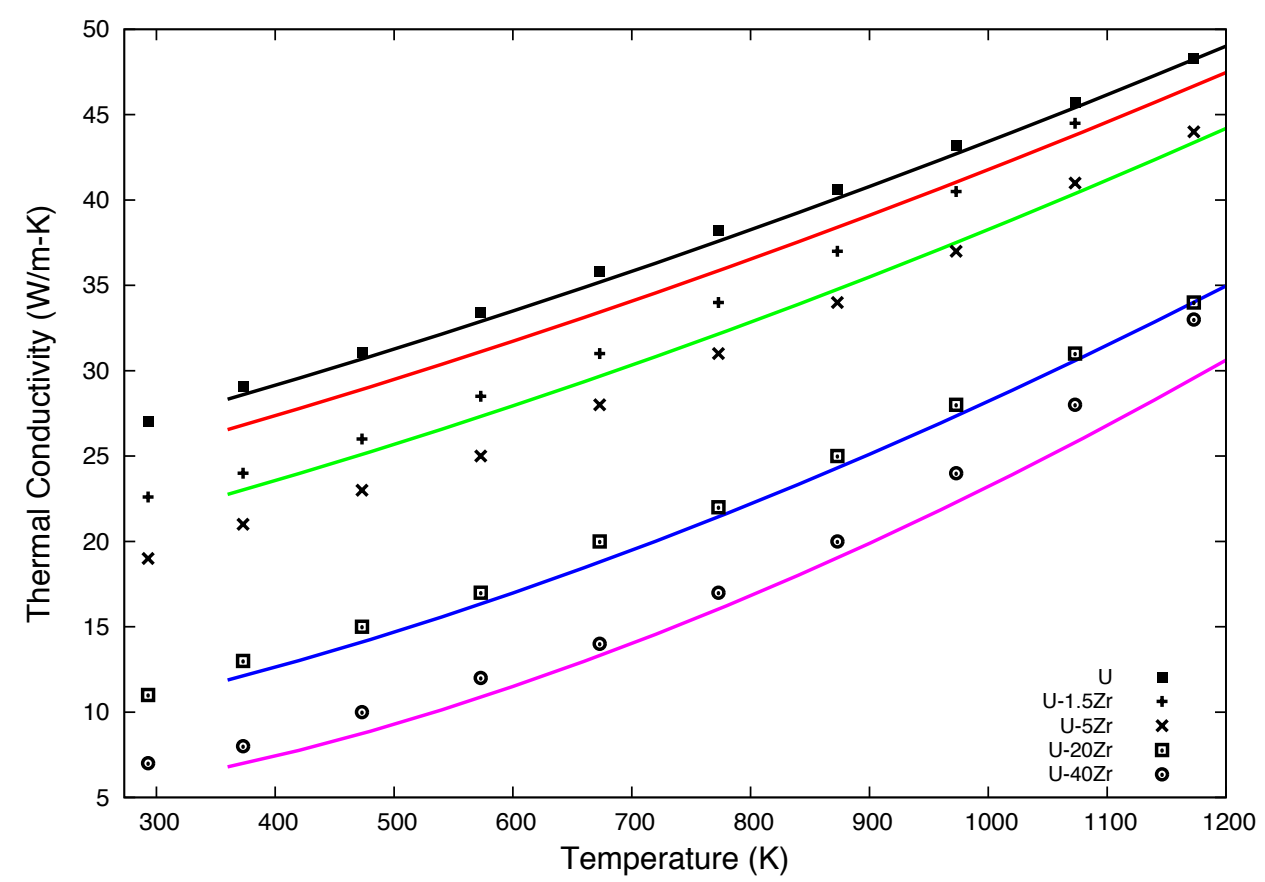

Figure 3.2: Comparison of Bison (LANL model) and Metallic Fuels Handbook Data

Additional comparisons of this type using separate effects experimental data are planned in the future for the areas of material creep, swelling, diffusion and other important physical processes occuring in metallic fuels. These efforts will be essential to both verify model implementation in Bison and establish the robustness of the models. 


\section{Comparing EBR-II measurements to Bison Calculations}

There are many figures of merit that could potentially be used to quantify Bison's simulation capability regarding metallic fuel. Recall, we're solving for temperature, zirconium concentration, and displacements, so it's obvious to want to compare Bison's calculation of those values to measurements recorded in an experiment. However, there aren't any temperature measurements for EBR-II fuel pins. There are calculations for temperature that were performed at the time of the experiments, some zirconium concentration data and several cladding diameter measurements. So, we've chosen to focus on comparing cladding strain/displacement measurements. The degree to which Bison predicts final cladding diameter is a good overall metric of how all the material models are working together, because temperature has a strong influence on final cladding diameter. Also shown is a comparison to final zirconium distribution in the fuel and a peak inner cladding temperature calculation. The calculations and EBR-II measurements presented here are of fuel pins from experiments called X447 and X441.

A fact that is more appreciated after reviewing the EBR-II data and performing Bison calculations is that plenum pressure strongly affects cladding displacements (final cladding diameter measurements), probably more than any other single parameter. Although the fuel swells quickly and comes in contact with the cladding, the fuel doesn't drive the cladding outward because the fuel is soft compared to the clad. This applies to low burnup (perahps $<10 \%$ ). Therefore, the force driving displacement of the cladding is the difference between plenum and coolant pressure. The coolant pressure is constant at about $0.151 \mathrm{MPa}$ and the plenum pressure starts out at $0.084 \mathrm{MPa}$. As fission gas is released, the plenum pressure increases to $10 \mathrm{MPa}$ (according to our calculations) at peak burnup (about $10 \%$ at the end of the simulation). This delta P (10 $0.151 \mathrm{MPa}$ ) drives the cladding mechanical response. So it would seem fission gas release, and the mechanics that drive it, are very important to model if accurate cladding diameter strains are to be calculated. As mentioned in section 2 fission gas release depends on porosity, which is calculated by the gaseous swelling model; derived from a force balance applied to a bubble in the fuel. Part of that force balance (see 3.3.3) is hydrostatic stress in the fuel. This means, to put it simply, that the stress state in the fuel, governed by the mechanics models (elasticity, creep, thermal expansion and conductivity) greatly influence fission gas release. If these complicated and interconnected models are inaccurate, the fission gas release will be wrong, leading to errors in predictions of cladding strain. As shown in the results section (4.2 and 4.3), the models applied in Bison do a reasonable job of reproducing cladding strain. However, the swelling model does not provide enough expansion in the radial direction, so the fuel and cladding never contact throughout the simulation (with the exception of the $85 \%$ smeared density case). We know 
from micrographs from EBR-II that, in fact, fuel and cladding do contact. Going forward, fuel mechanics models will be developed that drive the fuel toward the cladding without much force upon contact, such that reasonable prediction of cladding mechanical response is maintained.

\subsection{Description of X447 and X441 Experiments}

There are many EBR-II tests that would serve as adequate validation cases. Our first attempt at evaluating/validating the metallic fuel simulation capability in Bison was to find an experiment with representative power, geometry, and initial/boundary conditions which recorded data such as clad strain, fission gas release, temperature, $\mathrm{Zr}$ distribution, and plenum pressure and compare those to measurements from similar experiments. The DP11 pin from X447a and the pins DP21, DP31, DP49, DP55, and DP61 from experiment X441 were found to provide the required data. Table 4.1

\begin{tabular}{|c|c|c|}
\hline Quantity & Source & Files \\
\hline Plenum Pressure and Volume & EBR-II data files & elm_data and elm_design CSV files \\
\hline Cladding Hoop Strain & EBR-II data files & X447a/X441 Element Laser Profile PDF file \\
\hline Power & EBR-II data files & elm_temp and run CSV files \\
\hline Coolant Conditions & EBR-II data files & sub_neutronics and sub_design CSV files \\
\hline Geometry & EBR-II data files & elm_data and elm_design CSV files \\
\hline
\end{tabular}

Table 4.1: The data files used for the gathering the EBR-II measurements

The EBR-II experiments were designed to test (in part at least) fuel response as a function of fuel alloy composition, smear density, plenum to fuel volume ratio, power, and coolant conditions. The experiments X441 and X447 are similar, but differ in a few key ways as shown in 4.2.

\begin{tabular}{|c|c|c|}
\hline Experiment/Assembly Number & X447 & X441 \\
\hline Fuel Type & U10Zr & U19Pu10Zr \\
\hline LHR kW/m & 29 & 44 \\
\hline Final Burnup at.\% & 10 & 12.5 \\
\hline Fast Neutron Flux n $/ \mathrm{m}^{2}$-s $* 1 \mathrm{e} 19$ & 0.6 & 2.47 \\
\hline Coolant Mass Flux kg/m ${ }^{2}$-s & 2473 & 5261 \\
\hline Coolant Pressure MPa & 0.151 & 0.151 \\
\hline Coolant Temperature K & 650 & 650 \\
\hline Pin Number & DP11 & DP31, DP21, DP46, DP55, DP61 \\
\hline Plenum to Fuel Volume Ratio & 1.5 & $1.1,1.5,2.1$ \\
\hline Smear Density\% & 75 & $70,75,85$ \\
\hline
\end{tabular}

Table 4.2: Experiment features for X441 and X447

Table 4.3 shows nominal model geometry for the fuel pins used in these calculations, which are subject to change based on plenum to fuel volume ratio and smear density specified in Table 4.2. 
For example, the plenum height could be changed to $0.193 \mathrm{~m}$ and to $0.295 \mathrm{~m}$ for plenum to fuel volume ratios of 1.1 and 2.1 respectively.

\begin{tabular}{|c|c|}
\hline Fuel Length & $0.343 \mathrm{~m}$ \\
\hline Fuel Radius & $2.2 \mathrm{~mm}$ \\
\hline Gap Size & $348 \mu \mathrm{m}$ \\
\hline Cladding Thickness & $381 \mu \mathrm{m}$ \\
\hline Plenum Height & $0.270 \mathrm{~m}$ \\
\hline Pin Diameter & $5.84 \mathrm{~mm}$ \\
\hline Pin Pitch & $6.91 \mathrm{~mm}$ \\
\hline
\end{tabular}

Table 4.3: Nominal fuel pin geometry for a plenum to fuel volume ratio of 1.5 , which is typical of EBR-II pins.

\subsection{Results - X447 Binary Fuel}

Showing results from experiment X447 in this section, which is binary fuel. Results shown are cladding deformation, temperature calculations, fission gas release, and zirconium redistribution.

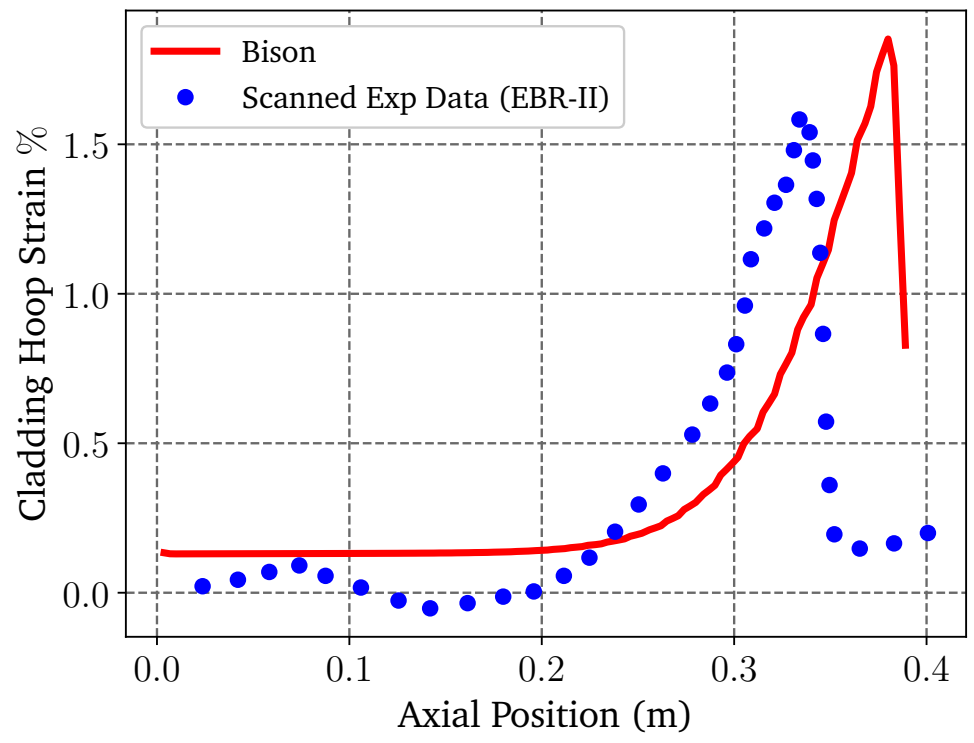

Figure 4.1: Cladding hoop strain vs. axial position. The difference in peak strain is likely due to the model swelling too much in the axial direction; peak strain is thought to occur at the top of the fuel column. 


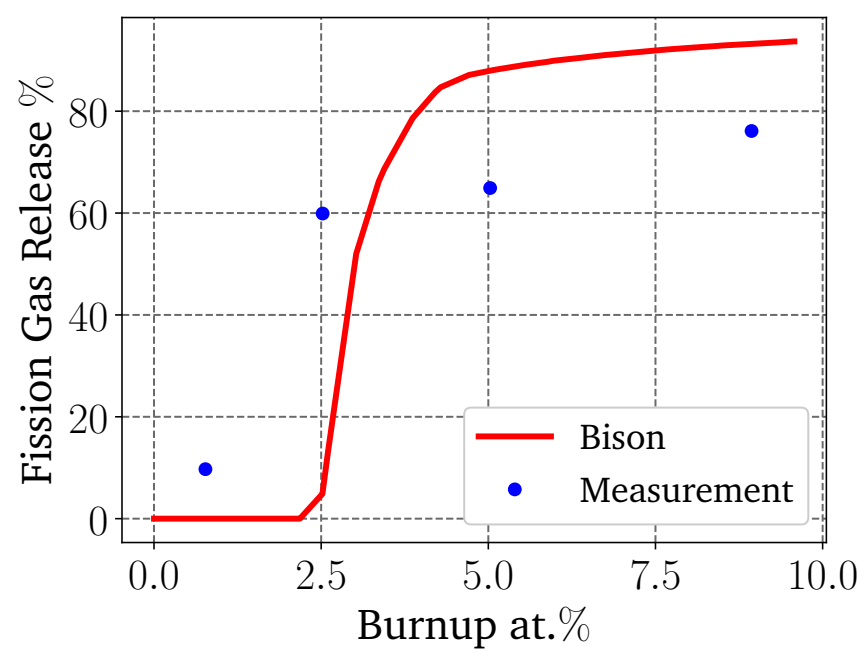

Figure 4.2: Fission gas release vs. burnup in at.\%. Eighty percent of the fission gas generated is released when the porosity reaches $25 \%$, after which all fission gas is released as it's generated. The assumption that $25 \%$ porosity is the value where pore interconnection occurs has a large effect on fission gas release and therefore plenum pressure and cladding deformation.

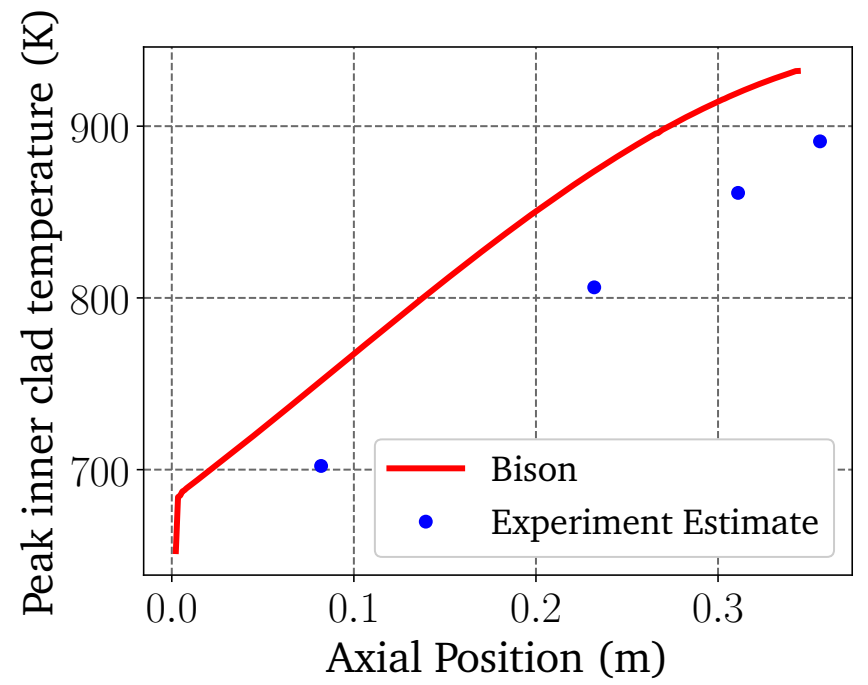

Figure 4.3: Peak inner cladding temperature vs. axial position. While no temperature measurements were recorded, calculations of expected temperature where performed at the time of the experiment. These values compared to Bison calculations are shown here for comparison. 


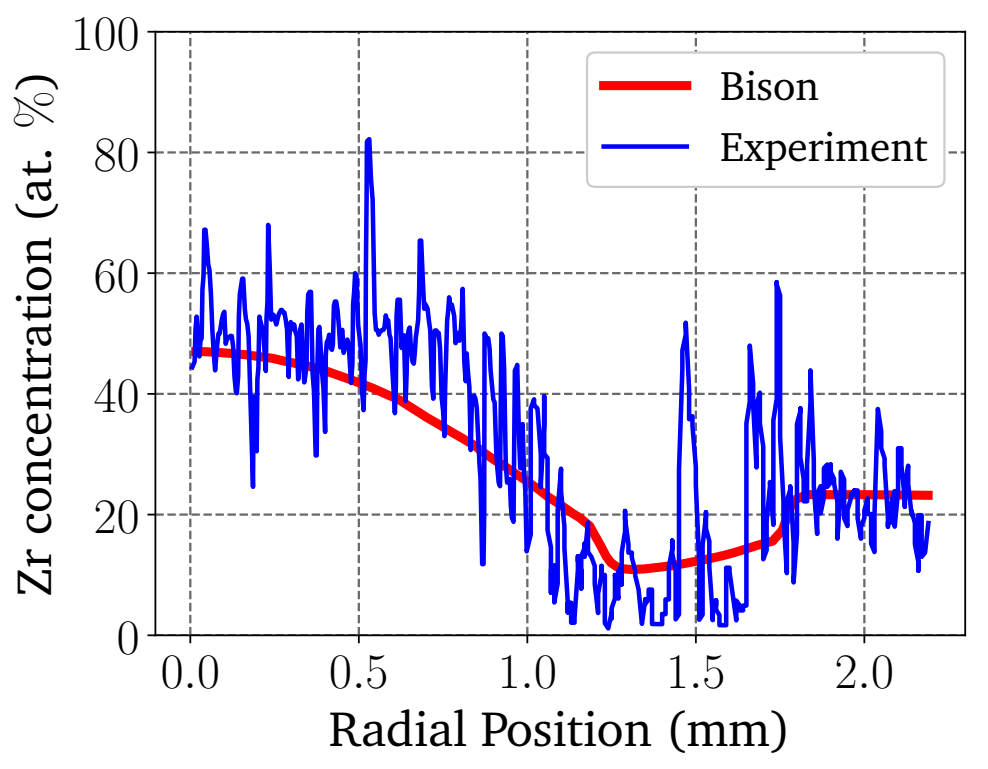

Figure 4.4: Zirconium distribution vs. radial position in the fuel. The plot shows the expected bathtub shape from the middle of the fuel outward and the increase of $\mathrm{Zr}$ at the center. Simulation convergence issues are often encountered when solving Equations 3.1, 3.2, and 3.3 fully coupled. The results shown here are from a fully coupled simulation, although the creep model in the fuel was disabled, which is known to make convergence easier. Work in FY19 will focus on investigating convergence robustness approaches, such as Picard iteration, various scaling approaches, and PETSc solver options. 


\subsection{Results - X441 Ternary Fuel}

Results are shown in this section for X441, which is ternary fuel, at various plenum to fuel volume ratios and smear density ratios.

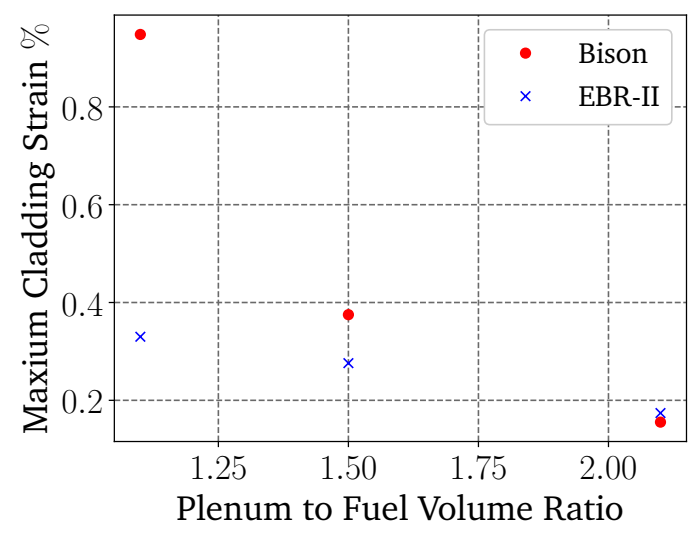

Figure 4.5: Maximum creep strain vs. plenum/fuel volume ratio for X441 pins DP31, DP21, DP55. The large differnce between the Bison result and measurement is thought to be due to an overestimate of plenum temperature calculation, which we will address in FY19.

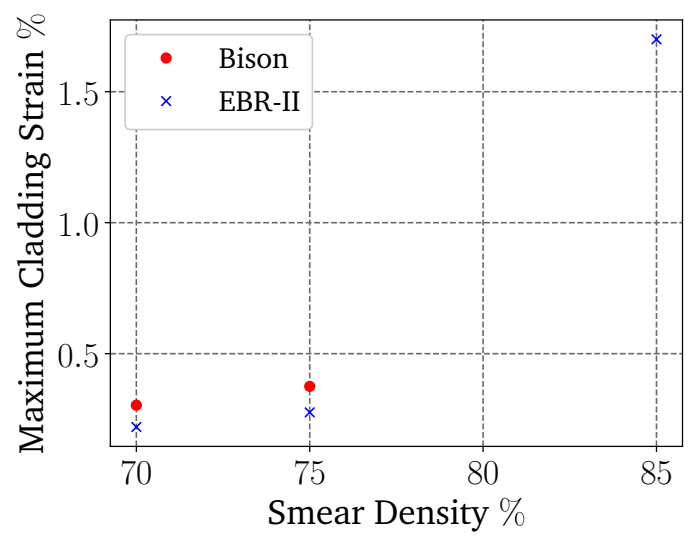

Figure 4.6: Maximum creep strain vs. smear density for X441 pins DP61, DP21, and DP49. Note the lack of a Bison result at $85 \%$ smear density. We speculate that this is due to contact between fuel and cladding before pore interconnection occurs. This leads to large swelling while in contact, which could cause convergence issues. Also, the swelling model (Equation 3.11) is unstable with large positive values of hydrostatic stress. 


\subsection{Discusion of X441 and X447}

Results show that Bison calculations compare reasonably well with EBR-II measurements, with the exception of maximum cladding strain when the plenum to fuel volume ration is low in Figure 4.5. This can probably be explained with the current method used in Bison to calculate the plenum temperature, which was originally designed for LWR fuel, and likely overestimates plenum temperature in liquid-metal-cooled fast reactors. Also, the simulation for $85 \%$ smear density didn't run to completion. We speculate that this is due to contact between fuel and cladding prior to porosity interconnection, which would lead to large swelling during contact that could cause convergence issues. This convergence trouble could also be caused by the gas swelling model of Equation 3.11, which has been found to be problematic when hydrostatic stress values are large and positive. Improvements to the swelling model are a high priority for FY19.

The axial offset of peak hoop strain in Figure 4.1 is likely due to the swelling model, which we know under-predicts radial swelling. This leads to an over-estimate of axial strain in the fuel. This is important because the peak hoop strain is coincident with the top of the fuel column. In FY19, we plan to investigate and improve material models and expect to see better comparisons to measurements as a result.

\subsection{Comparison to the TREAT M7 Experiment}

An additional assessment case is presented here to show a comparison of Bison temperature calculations to experiment measurement. A subset of EBR-II fuel rods subjected to transient power pulse in the Transient Reactor Test Facility (TREAT) reactor. In this case, we focus on the M7 experiment, the details of which are found in a report by Bauer [23] with a brief overview presented here. The M7 test tested two EBR-II irradiated fuel pins: a 9.8 at\% burnup U-19Pu$10 \mathrm{Zr}$ clad in D9 and a 2.9 at\% U-10Zr clad in HT9. During the TREAT transient test, the ternary pin alone failed. A Bison model of the M7 test has been selected to illustrate model needs within Bison and as a guide for modeling metallic fuel transients from historic TREAT tests. The example currently only includes the heat conduction model of the binary $\mathrm{U}-10 \mathrm{Zr}$ pin. The heat conduction model is able to verify that the provided heat profile is indeed correct. Further development will include mechanical models and expand to modeling the failed pin.

The problem domain consisting of the geometry, boundary conditions, initial conditions, heat source functions, and some material properties that are found in the report. The example input file in Bison notes the location in the report from which each value is taken.

As the binary pin had some burnup, the amount of Pu produced during burnup is calculated and supplied as an initial condition for the transient. Possible future work may supply this initial condition with a burnup simulation starting with fresh fuel in EBR-II.

The following Bison $\mathrm{C}++$ classes specific to metallic fuel are currently active in the input file: 
- ThermalUPuZr - Savage Specific Heat Correlation, Billone Thermal Conductivity Correlation

- ThermalHT9

- CoolantChannel - Seban/Shimazaki Sodium Heat Transfer Correlation - see section 3.4

The transient test in TREAT used a tube with flowing sodium around the pin. This required a sodium heat transfer correlation specific to tube flow leading to the use of the Seban and Shimazaki correlation.

The comparison of the Bison 2D-RZ transient model overlaid on the binary U-Zr results, Figure 4.7 taken from the report [23], shows the simple heat conduction model simulation results. The report's value is from the outer radius temperature of the sodium flowtube where a thermocouple was located at the probable maximum temperature location. The Bison value is the maximum temperature at any position along the outer cladding radius as the flow tube is not modeled in Bison. Also, the report's figure is slightly distorted at the bottom right making proper axis alignment difficult.

Without knowing the uncertainty of the report's data or the actual temperature drop across the sodium coolant and flow-tube wall, the Bison temperature of the simple heat conduction model is a favorable result. Of particular interest is the rise in temperature at $8 \mathrm{~s}$ before the report's temperature rise. This may be due to the location of the Bison maximum value being allowed to move along the cladding wall. The report's data also shows the temperature continues to rise for a short time after "Time of Pin Failure," when the ternary pin failed initiating the reactor scram. Even though the power generation has plummeted, the report's data peaks in temperature while the Bison result immediately starts to cool. The coolant channel model and the ability of the maximum temperature location to change position give rise to the discontinuities in the cool down stage after pin failure. The difference in final temperature may be due to the discrepancy of the peak temperature and some figure distortion.

One of the largest uncertainties of the example is the power profile. The report provides the profile but does not specify if the axial or radial peaking factors are included or if the power is an average or maximum power. The example results ignore the radial profile and only include the axial peaking factors. Including the radial peaking factors produces outer clad temperatures inconsistent with experimentally reported values, leading to the conclusion that the radial profile is already included into the reported power profile. The reproduction of the power density profile in Figure 4.7 is evidence in support of this conclusion.

This inclusion is not desirable for multi-physics as the power profile determines the temperature profile in the fuel. Multi-physics coupling with mechanical models and mass transport models are both affected by the temperature profile. Further work is needed at interpreting the data provided in the report with simulation modeling verifying the assumptions. Simulated models should be able to separate the radial peaking factors from the reported power profile and still be consistent with experimental values. 

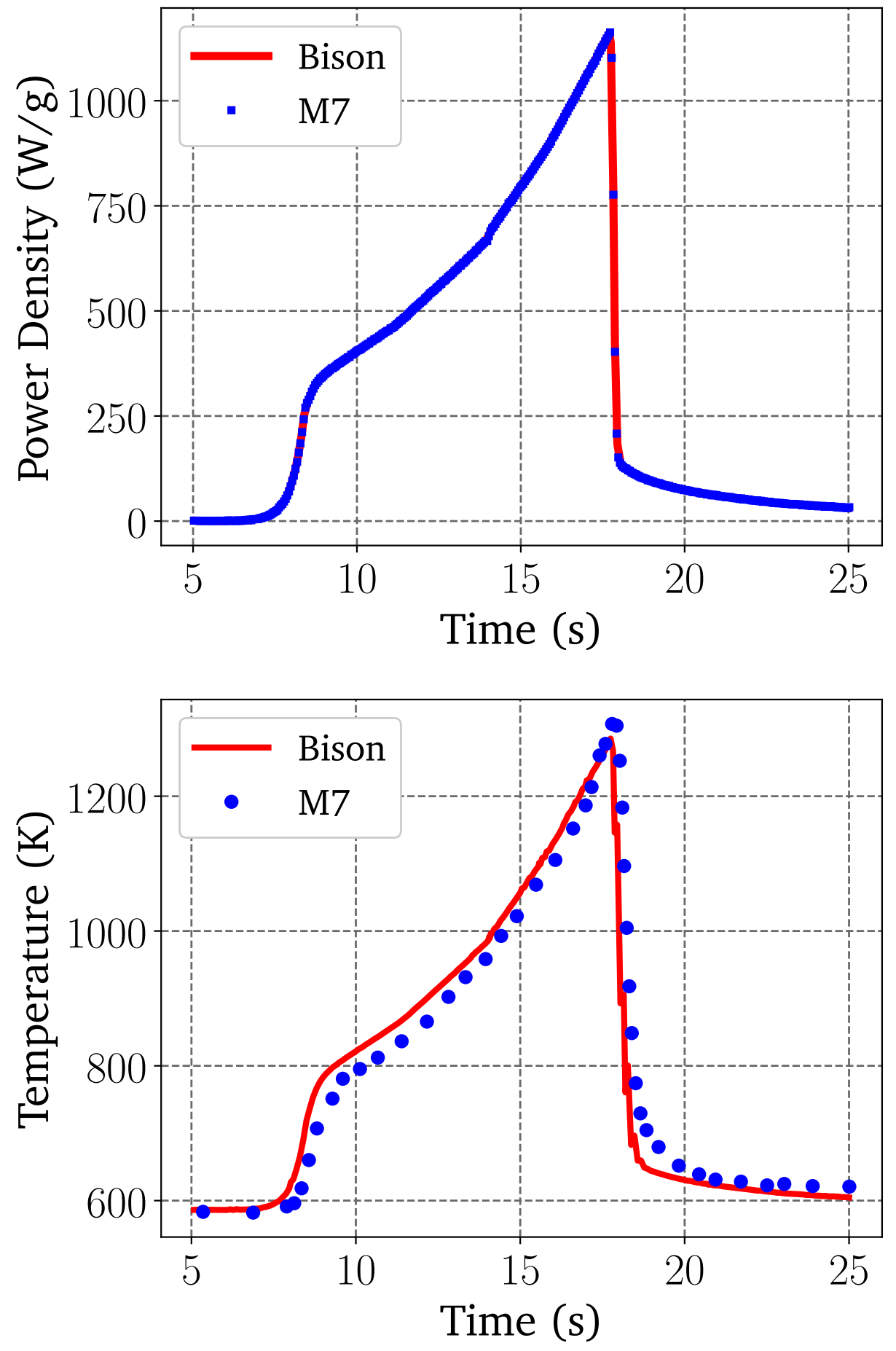

Figure 4.7: Comparison of Bison model to power and temperature measurements from [23]. 


\section{Calculations in Support of Experiment Design}

The metallic fuel capability in Bison has been used in support of experiment design. In this section, we show examples of such calculations for ATR and VTR.

\subsection{ATR Experiment Design Calculations}

Furnace testing of irradiated metallic fuel is planned by Advanced Fuel Campaign to provide time-to-failure data that will be helpful in the benchmarking of fuel performance models and in assessing the performance of new fuel designs relative to more standard fast reactor fuel systems [24].

To illustrate Bison capability to model metallic fuel irradiation and furnace testing, irradiation and furnace testing of AFC-3D-R1 was simulated. AFC-3D-R1 was an annular U-10Zr fuel rodlet irradiated in the ATR to a burnup of 4.59(ECAR-3392). For the purposes of this simulation, to accentuate the impact of the furnace testing, the rodlet plenum was reduced by a factor of 10 compared to an actual AFC-3D-R1 rodlet.

Results of the simulation of AFC-3D-R1 irradiation and furnace testing are shown in Figures 5.1 through 5.6. Figure 5.1 shows power history during irradiation. Figure 5.2 shows peak fuel temperature during irradiation and consequent furnace annealing. Figure 5.3 shows fission gas release, and Figure 5.4 shows plenum pressure. As evident from the results of the simulation, post-irradiation furnace annealing results in an increase of the plenum pressure. Increase of the plenum pressure causes accelerated deformation of the cladding as shown in Figure 5.5. Utilizing Bison cladding failure prediction capability, cladding failure is predicted after 31.5 hours of furnace annealing at $727 \mathrm{C}$ as shown in Figure 5.6. 


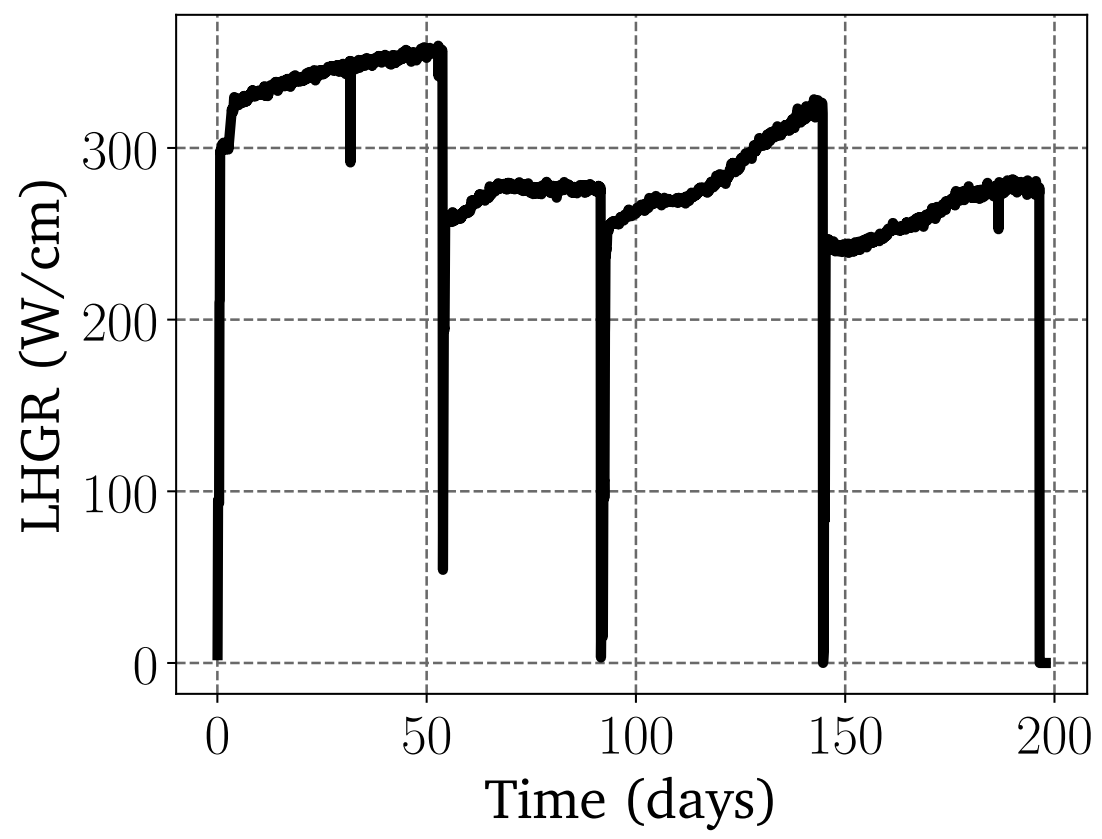

Figure 5.1: ATR Power

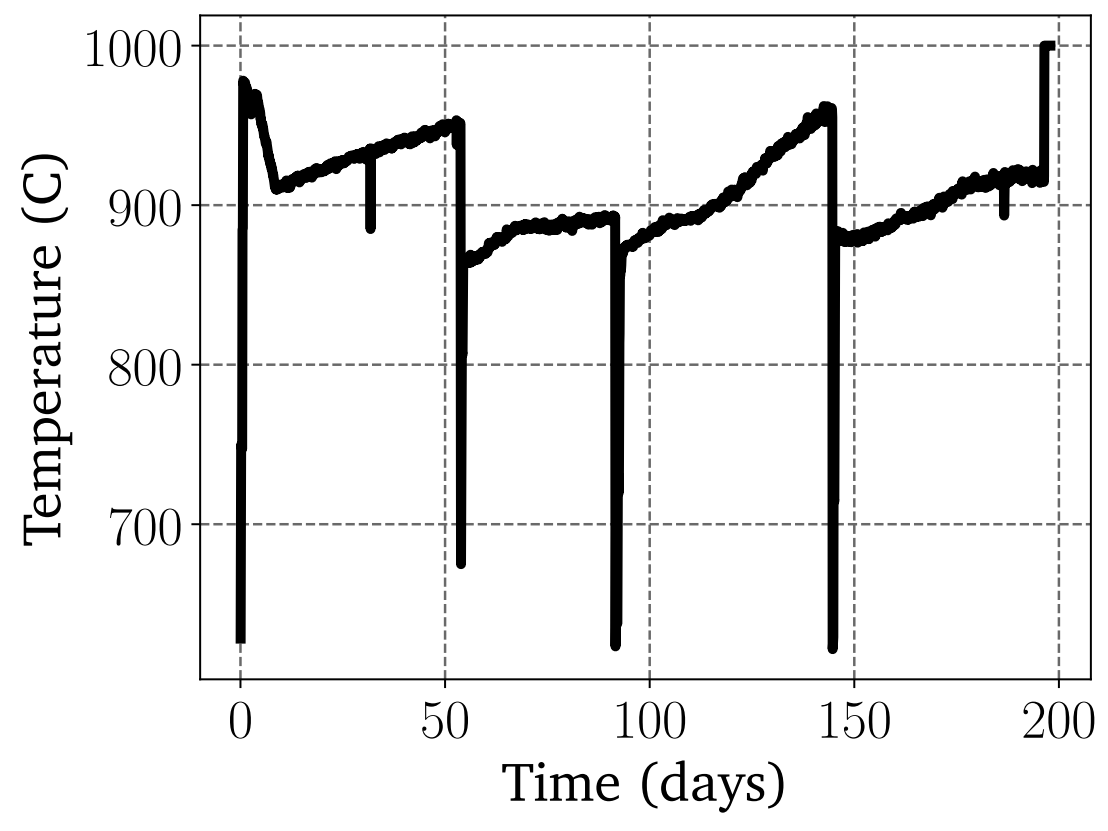

Figure 5.2: ATR peak fuel temperature 


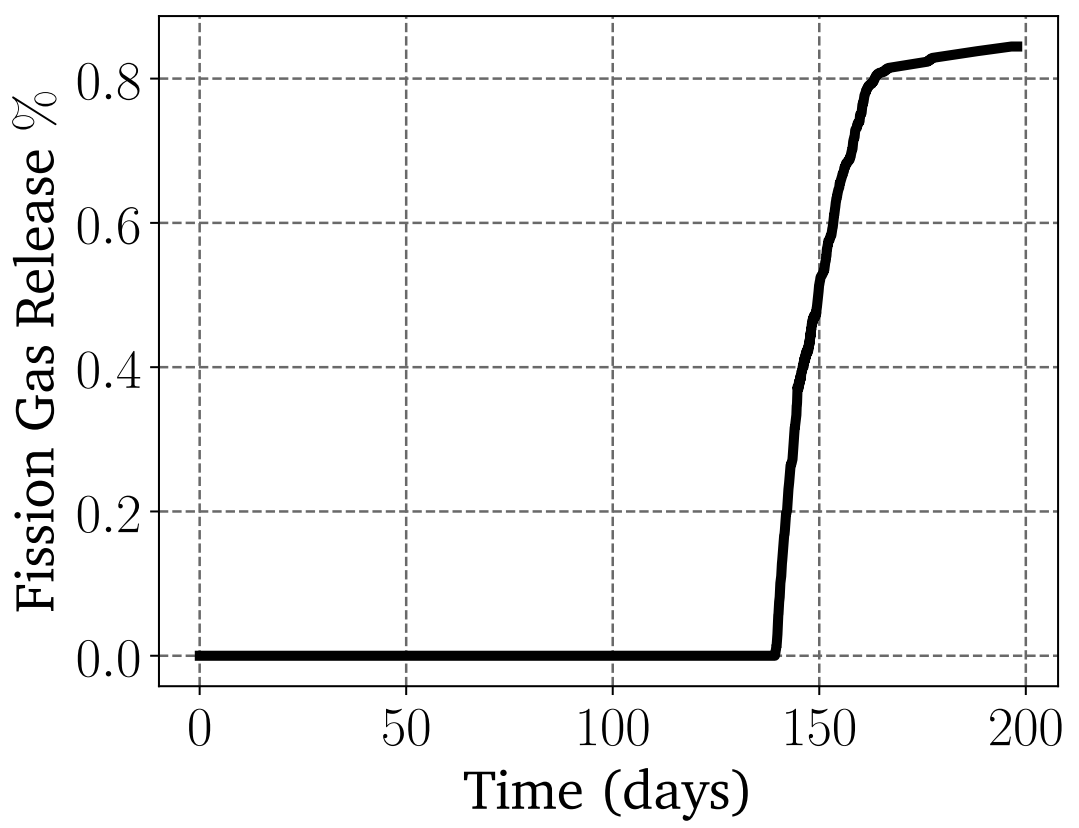

Figure 5.3: ATR fission gas release

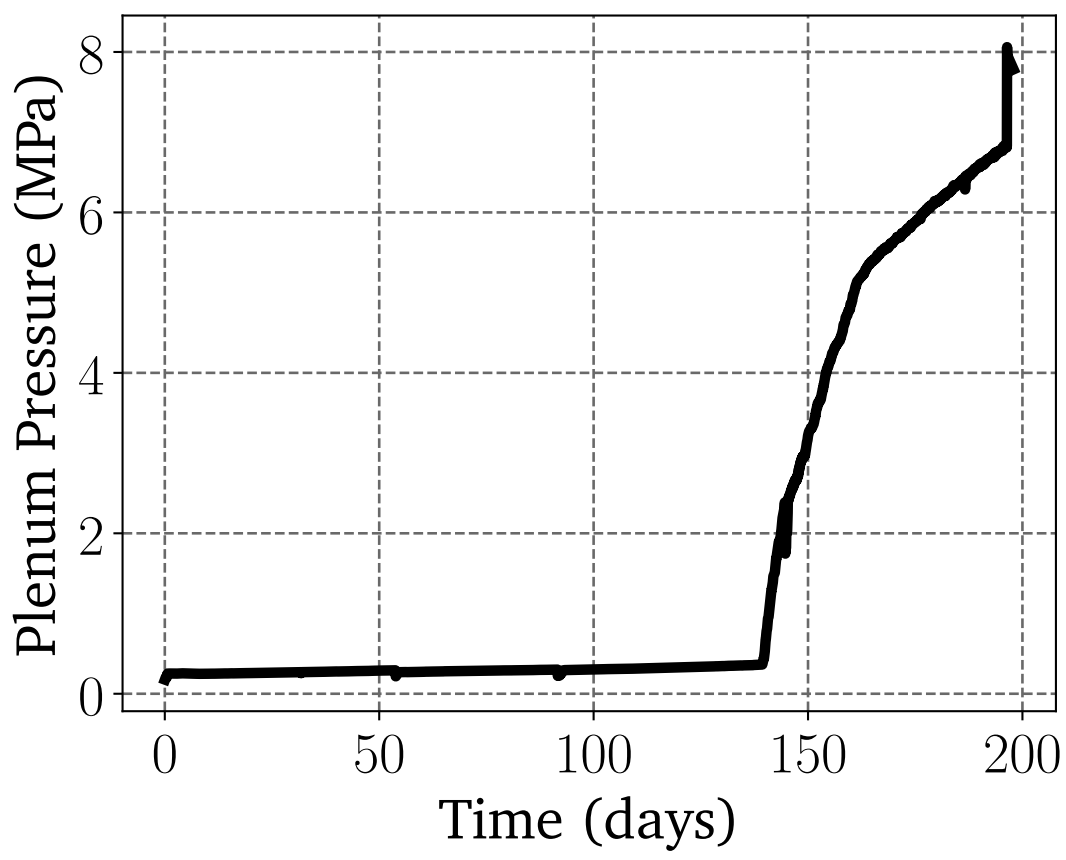

Figure 5.4: ATR plenum pressure 


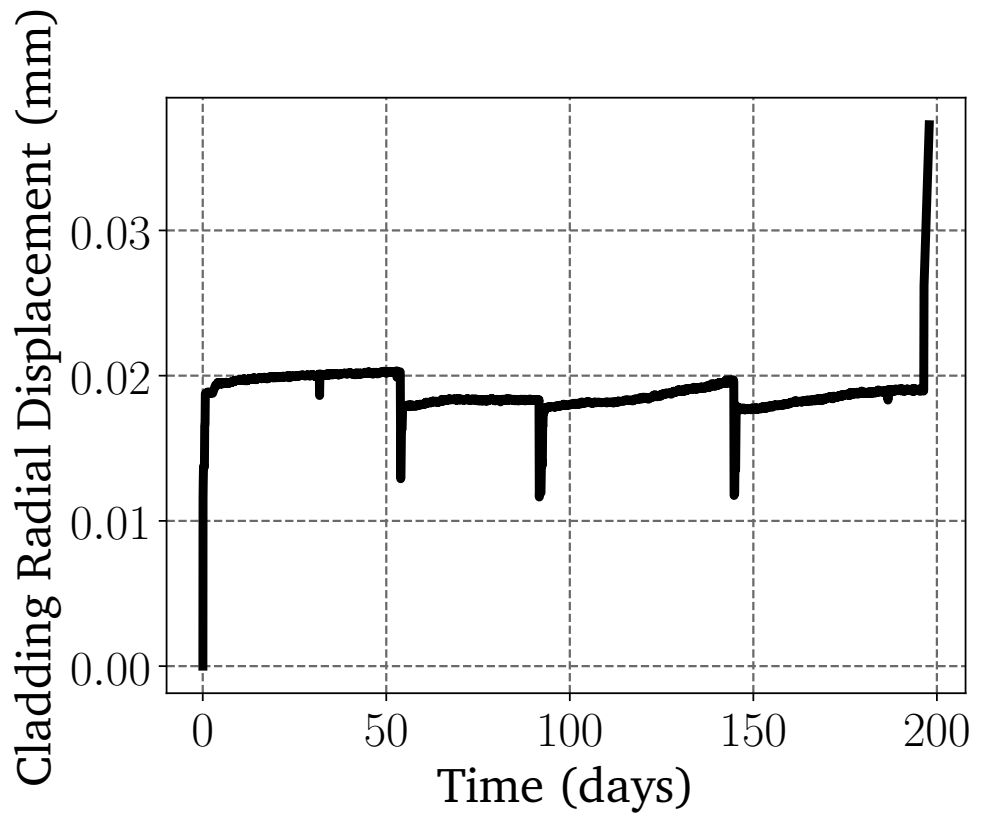

Figure 5.5: ATR cladding radial displacement

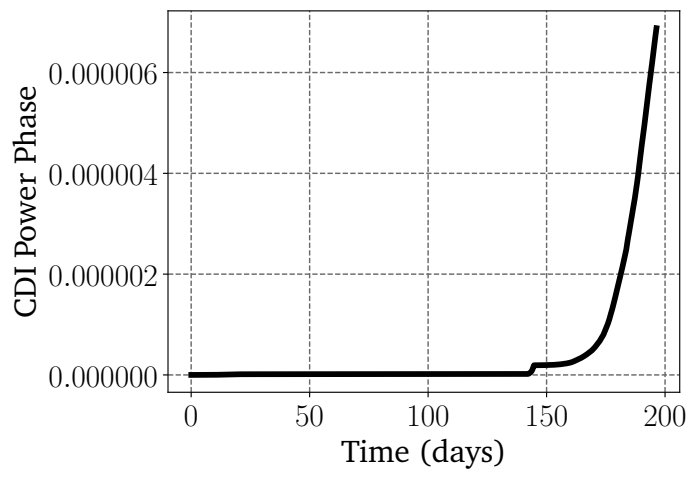

(a) Base Irradiation

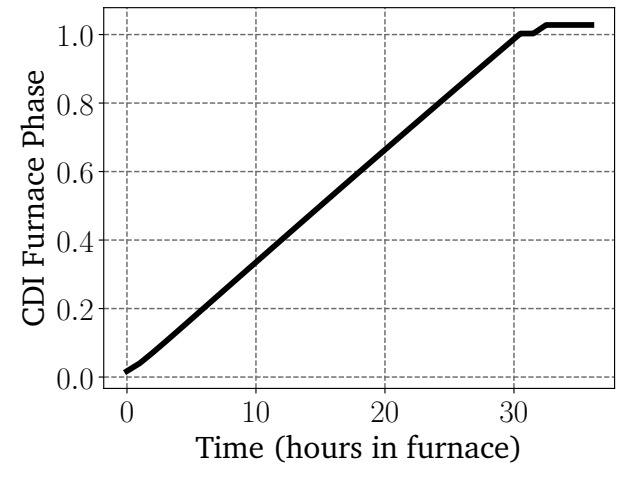

(b) Furnace Experiment

Figure 5.6: ATR cladding cumulative damage index for base irradiation and subsequent furnace experiment 
Fission release, cladding deformation, time to failure are the fuel performance metrics that will be compared with the results of post-irradiation examination. This simulation illustrates BISON use to plan, carry out and understand metallic fuel development activities such as irradiation design, in-pile and out-of-pile testing, and post-irradiation examination.

\subsection{Use of Bison for Modeling Deformation of Slotted Metallic Fuel}

Irradiation testing of slotted metallic fuel has been proposed by the Advanced Fuel Campaign (AFC) in order to develop high burnup fuel designs [24]. This advanced fuel design envisions pre-fabricated fuel slots designed to accommodate fuel swelling. The key challenge in utilization of the slotted fuel is understanding the evolution of the fuel slug geometry during irradiation. Closure of prefabricated slots without significant cladding strain is a desired behavior. Excessive cladding strain due to fuel swelling if slots fail to close, signifies undesired behavior.

Bison simulation of $\mathrm{U}-10 \mathrm{Zr}$ sodium bonded slotted fuel irradiation predicted favorable behavior under prototypic conditions. As shown in Figure 1, swelling and creep of the fuel cause prefabricated slots to close without significant cladding deformation. Figure 2 shows distribution of fission gas porosity in the fuel confirming that fuel deformation is driven by fission gas induced swelling. since AFC adopted Bison in 2012, BISON proved indispensable for screening of initial fuel concepts and design better performing nuclear fuels for advanced reactors. 


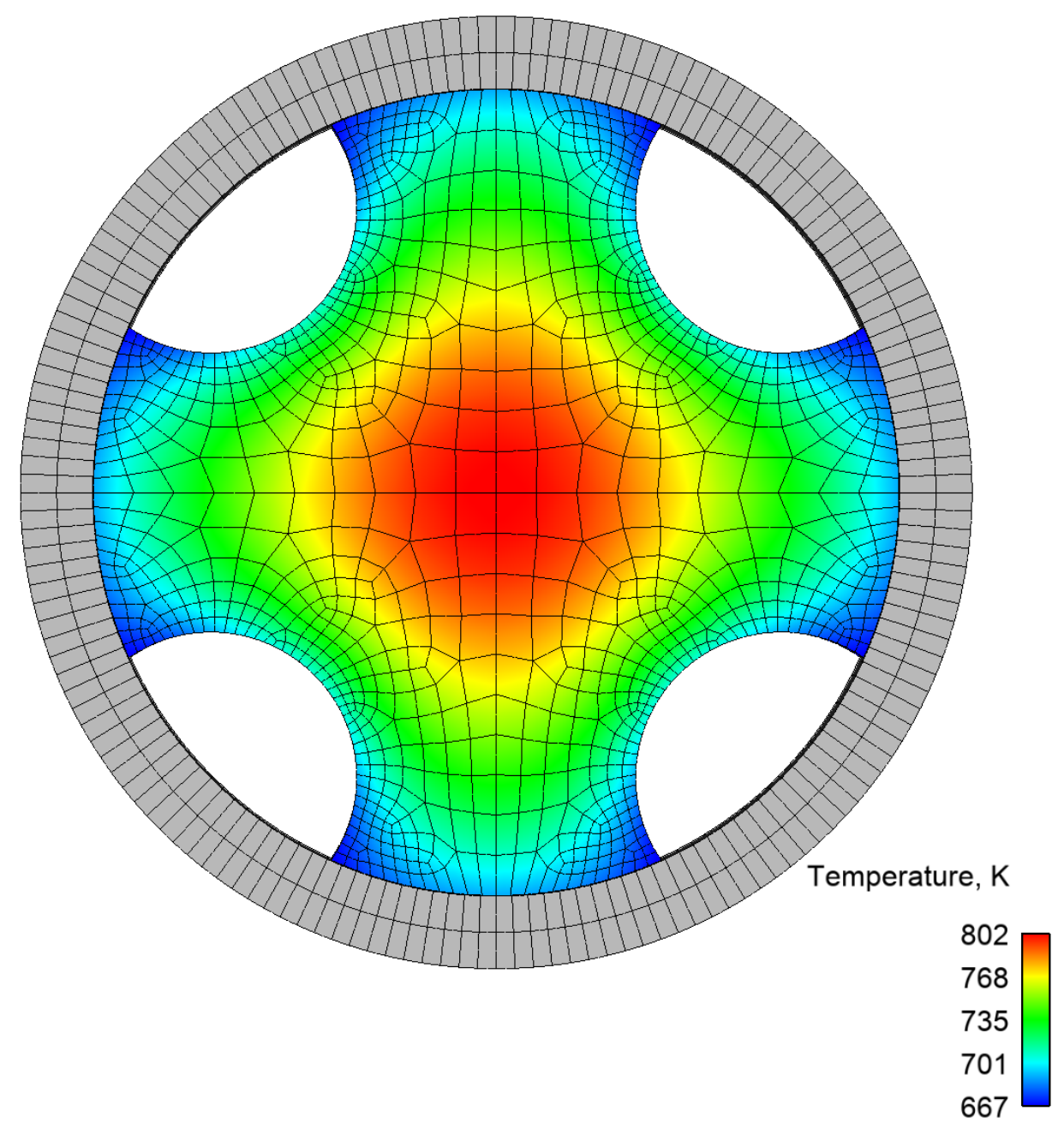

Figure 5.7: slotted fuel 


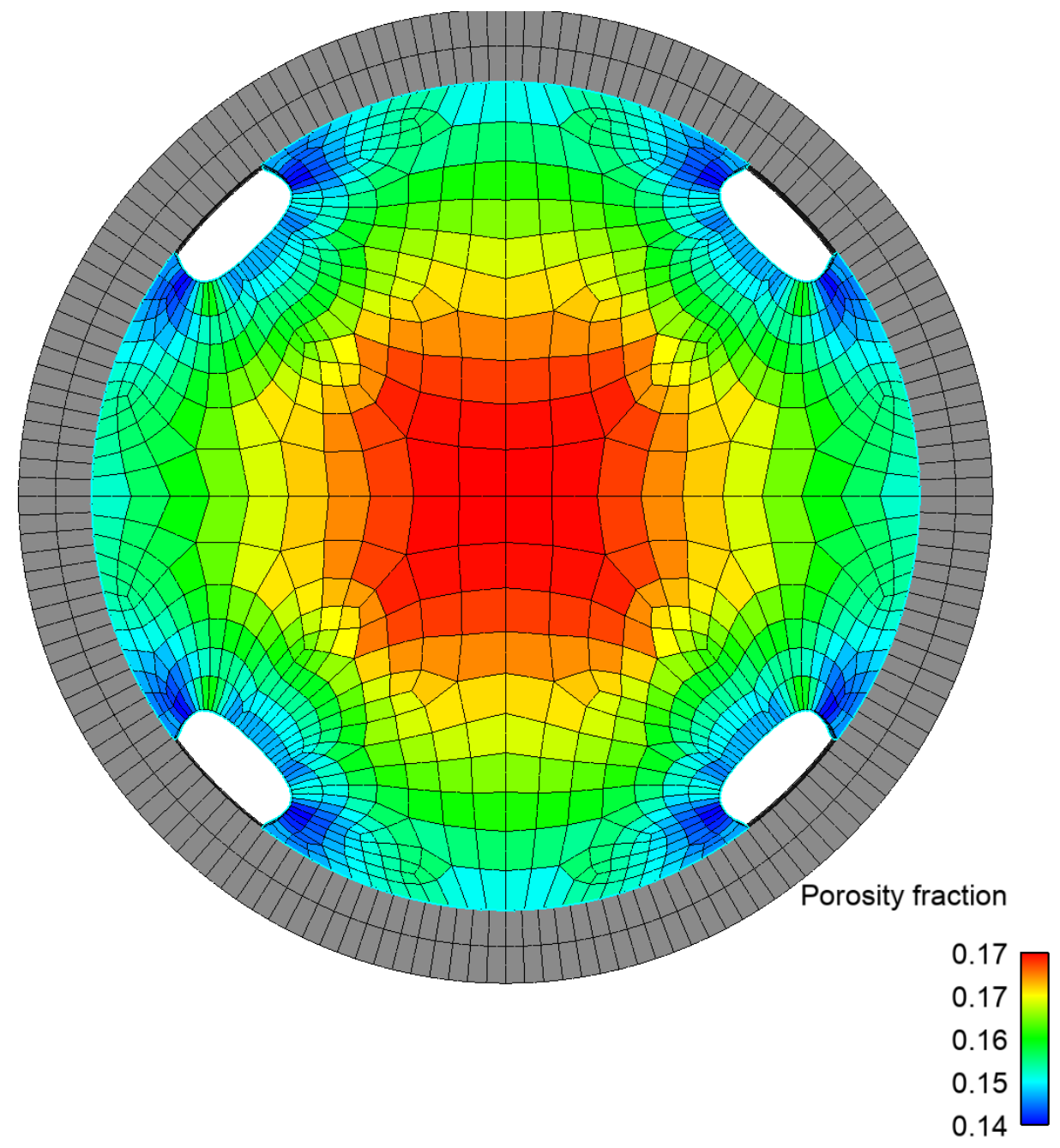

Figure 5.8: slotted fuel 


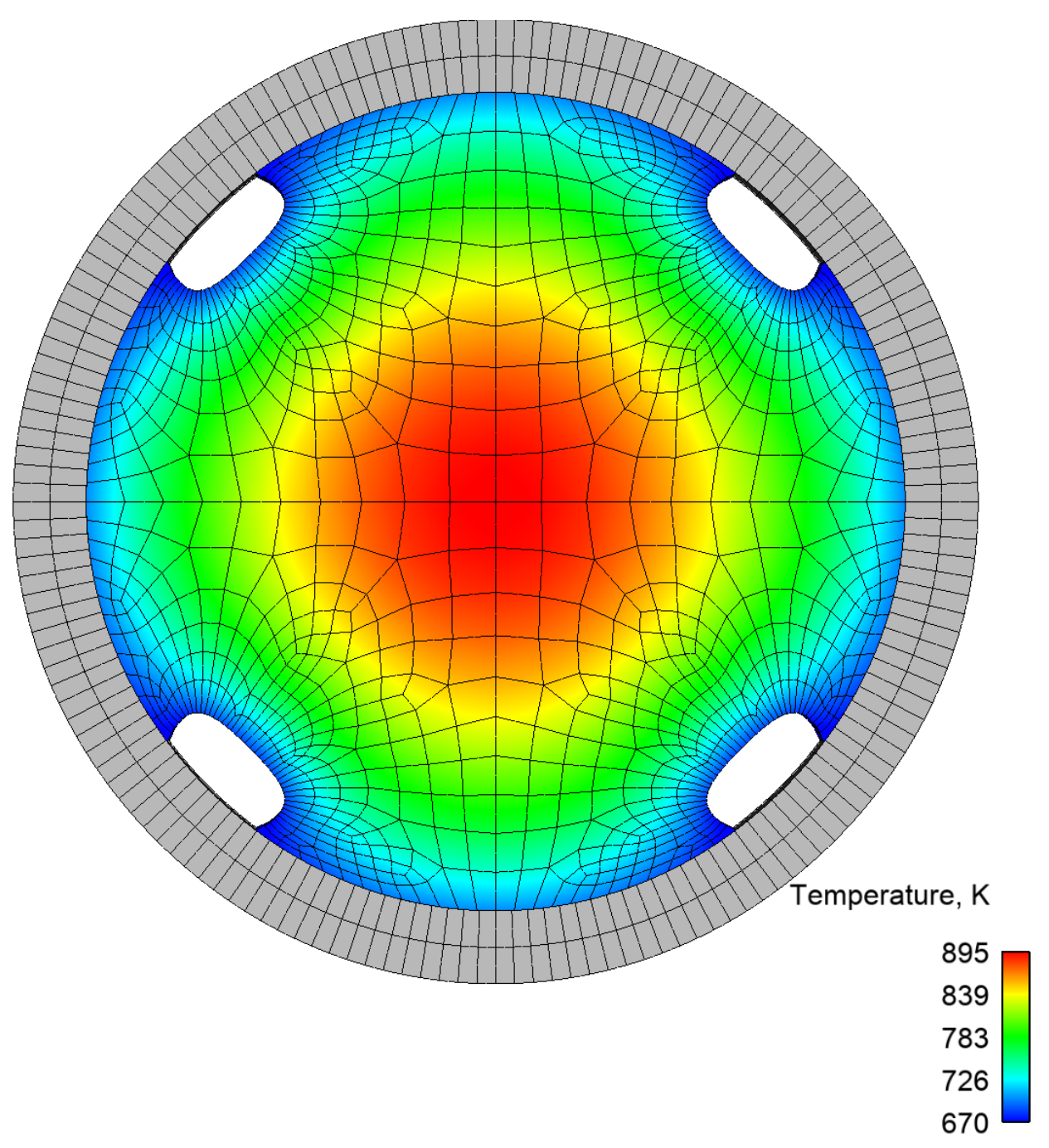

Figure 5.9: slotted fuel 


\subsection{VTR Exploratory Calculations}

An exploratory calculation was performed to estimate the effect of zirconium redistribution on thermal conductivity. Two simulations were run; one with zirconium diffusion enabled, and one where zirconium concentration was held constant. Figures 5.10 - 5.12 show calculations for zirconium concentration, temperature, fission rate, porosity, and thermal conductivity as a function of radial position within the fuel.
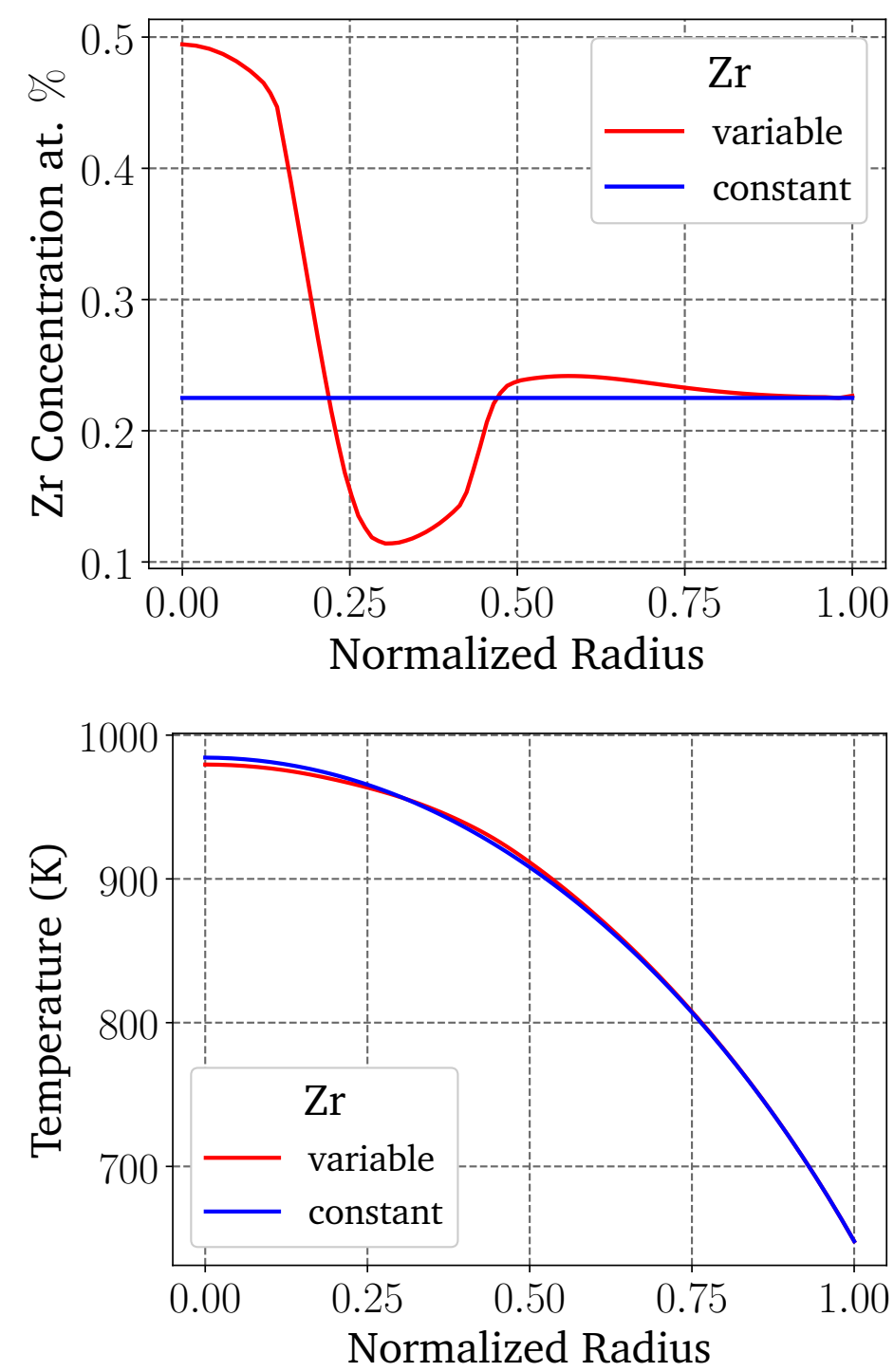

Figure 5.10: The effect of zirconium concentration on fuel thermal conductivity: zirconium concentration and temperature 

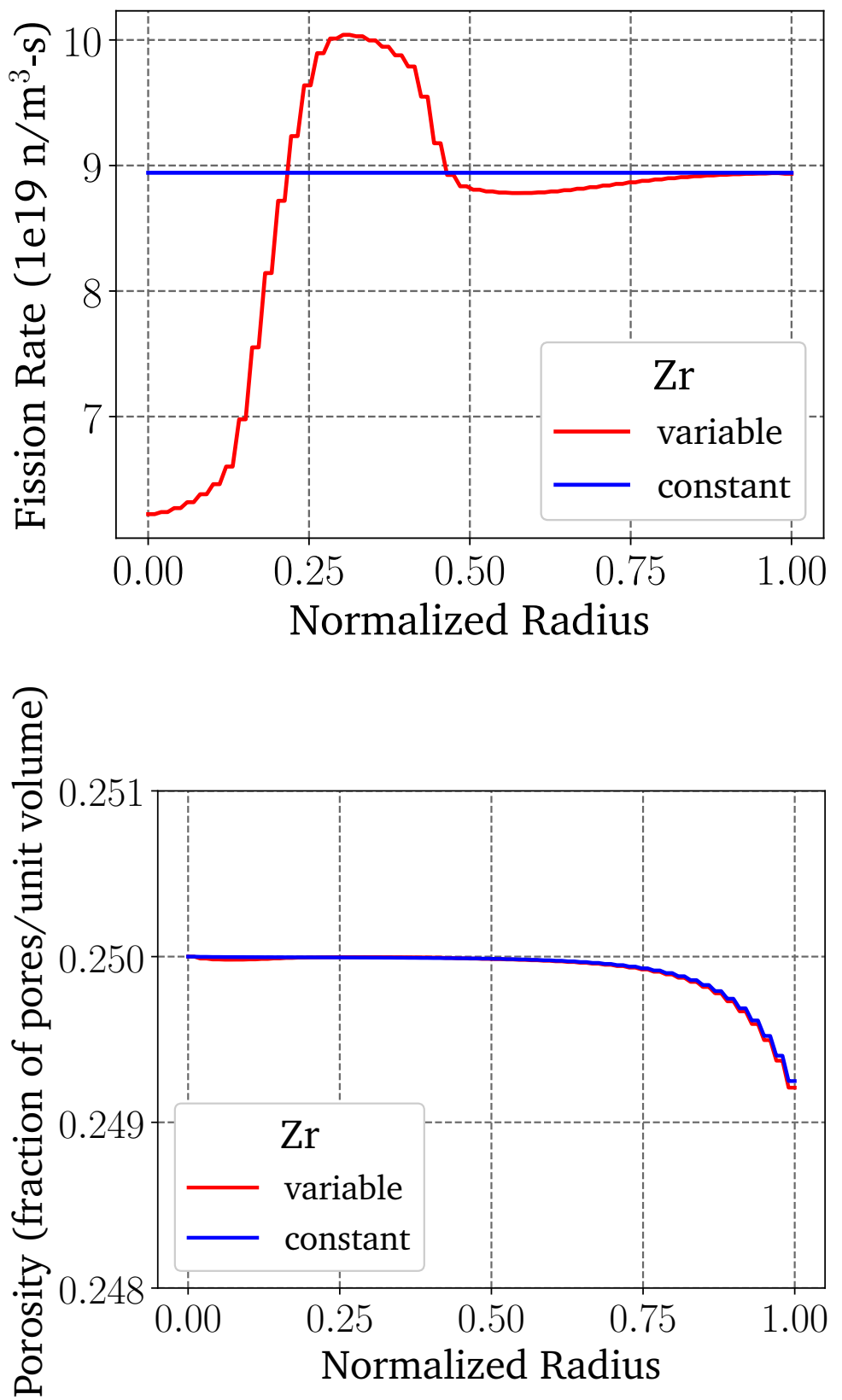

Figure 5.11: The effect of zirconium concentration on fuel thermal conductivity: fission rate and porosity 


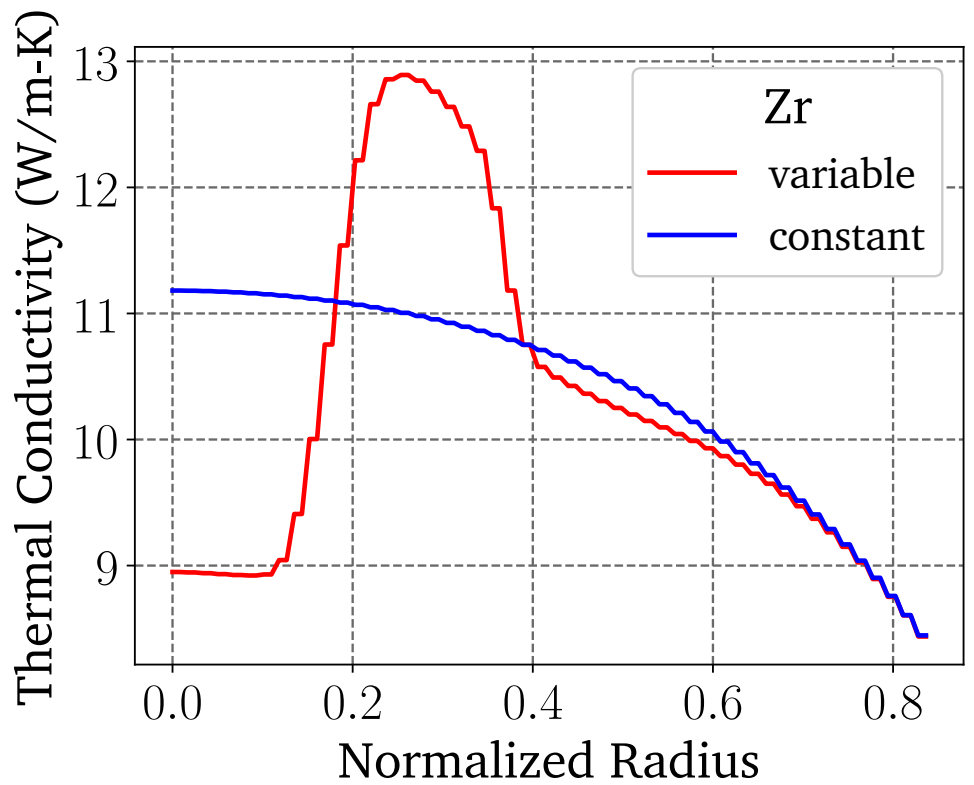

Figure 5.12: The effect of zirconium concentration on fuel thermal conductivity: thermal conductivity 


\section{Future Work}

\subsection{Additional Assessment Cases}

The EBR-II early operation with a variety of metallic fuel pin designs provides extensive experimental data to use in validating Bison models. The data on specific fuel pins can be extracted from archived EBR-II experimental results, but will require some additional work. The initial testing studies performed at EBR-II investigated various fuel pin design parameters in an effort to increase the burnup and minimize cladding failures. The following sections describe groups of fuel pins that were used across a number of test series to determine trends that could be used to improve the fuel pin design. These tests would be good candidates for Bison modeling efforts to confirm the ability of the code to predict the same trends in metallic fuel behavior.

\subsubsection{Effect of Plenum/Fuel Volume Ratio on Cladding Strain}

From test $\mathrm{X} 441$, group $\mathrm{A}(\mathrm{P} / \mathrm{F}=1.5)$, group $\mathrm{B}(\mathrm{P} / \mathrm{F}=2.1)$, group $\mathrm{C}(\mathrm{P} / \mathrm{F}=1.1)$. All these groups have the same fuel (U-10Zr) and cladding (HT9) with 75\% smear density.

1. Group A (DP15, DP16, DP21, DP22)

2. Group B (DP50, DP55, DP56)

3. Group C (DP35, DP36, DP37, DP39, DP40, DP41, DP42)

\subsubsection{Effect of Fuel Smear Density on Cladding Strain}

From test X441, group A (smear density=75\%), group F (smear density=85\%), group G (smear density $=70 \%$ ). The groups are similar in other respects except for the plenum/fuel volume ratio where group $\mathrm{F}$ has a value of 1.3 and the other groups are at 1.5.

1. Group A (DP15, DP16, DP21, DP22)

2. Group F (DP43, DP45, DP47, DP49)

3. Group G (DP61, DP62, DP63, DP64, DP67) 


\subsubsection{Effect of Zr Content on Cladding Strain}

From test X441, group A (Zr Conc=10\%), group D (Zr Conc=6\%), group E (Zr Conc=14\%). All the other characteristics of these tests is similar.

1. Group A (DP15, DP16, DP21, DP22)

2. Group D (DP23, DP24, DP25, DP26)

3. Group E (DP29, DP30, DP31, DP33)

\subsubsection{Effect of Cladding Material (D9/HT9) on Cladding Strain}

From test X441, groups A, D and E (HT9 clad material) \& groups I, J and K (D9 clad material). All the other characteristics of these tests is similar.

1. Group A (DP15, DP16, DP21, DP22)

2. Group D (DP23, DP24, DP25, DP26)

3. Group E (DP29, DP30, DP31, DP33)

4. Group I (A814, A831, A863, A875, A904)

5. Group J (A799, A812, A817, A841, A850, A876, C632, C648, C669, C694)

6. Group K (A597, A797, A866, A872) 


\section{Conclusions}

An initial metal fuel modeling capability has been implemented and demonstrated using the Bison fuel performance code. The material models necessary for simulations of $\mathrm{U}-\mathrm{Zr}$ and $\mathrm{U}$ $\mathrm{Pu}-\mathrm{Zr}$ metal fuels have been added to Bison. A preliminary set of assessment cases derived from historical EBR-II data have been created and some model predictions have been compared to experimental results. Although the comparisons between Bison and EBR-II results are encouraging, the robustness of the simulations need to be improved and some convergence issues remain unresolved. Additional advanced material models are being developed and will be merged into Bison when they are completed.

High-priority activities for FY19 will include adjusting the plenum temperature calculation to be consistent with fast-liquid metal-cooled reactors, investigate and implement more robust swelling models, improving convergence, and requiring more rigorous regression tests for individual material models and ensure robust material model interaction before these models are used in integrated simulation. 


\section{Acknowledgments}

This work was funded by the DOE Nuclear Energy Advanced Modeling and Simulation (NEAMS) program. The submitted manuscript has been authored by a contractor of the U.S. Government under Contract DE-AC07-05ID14517. Accordingly, the U.S. Government retains a nonexclusive, royalty free license to publish or reproduce the published form of this contribution, or allow others to do so, for U.S. Government purposes. 


\section{Bibliography}

[1] R. L. Williamson, J. D. Hales, S. R. Novascone, M. R. Tonks, D. R. Gaston, C. J. Permann, D. Andrs, and R. C. Martineau. Multidimensional multiphysics simulation of nuclear fuel behavior. Journal of Nuclear Materials, 423:149-163, 2012.

[2] J. D. Hales, S. R. Novascone, B.W. Spencer, R. L. Williamson, G. Pastore, and D. M. Perez. Verification of the BISON fuel performance code. Annals of Nuclear Energy, 71:81-90, 2014.

[3] C. Westfall. Vision and reality: The EBR-II story. Nuclear News, 47(2):25-32, February 2004.

[4] L. C. Walters. Thirty years of fuels and materials information from EBR-II. Journal of Nuclear Materials, 270:39-48, 1999.

[5] Leonard J. Koch. Experimental Breeder Reactor-II (EBR-II): An Integrated Experimental Fast Reactor Nuclear Power Station. American Nuclear Society, 2008.

[6] J. I. Sackett. Operating and test experience with EBR-II, the IFR prototype. Progress in Nuclear Energy, 31:111-129, 1997.

[7] R. G. Pahl, D. L. Porter, C. E. Lahm, and G. L. Hofman. Experimental Studies of U-Pu-Zr Fast Reactor Fuel Pins in EBR-II. Technical Report CONF-8809202-2, Argonne National Laboratory, 1988.

[8] Compiled by: IFR Property Evaluation Working Group. Metallic fuels handbook. Argonne National Laboratory, June 1988.

[9] T. R. G. Kutty, C. B. Basak, A. Kumar, and H. S. Kamath. Creep beahviour of $\delta$-phase of U-Zr system by impression creep technique. Journal of Nuclear Materials, 408:90-95, 2010.

[10] Pavel Medvedev. Fuel performance modeling results for representative FCRD irradiation experiments: Projected deformation in the annular AFC-3A U-10Zr fuel pins and comparison to alternative designs. Technical Report INL/EXT-12-27183 Revision 1, Idaho National Laboratory, 2012.

[11] R. S. Barnes. A Theory of Swelling and Gas Release for Reactor Materials. Journal of Nuclear Materials, 11:135-148, 1964. 
[12] Aydin Karahan. Modeling of thermo-mechanical and irradiation behavior of metallic and oxide fuels for sodium fast reactors. PhD thesis, Massachusetts Institute of Technology, June 2009.

[13] A. T. Churchman, R. S. Barnes, and A. H. Cottrell. Effects of Heat and Pressure on the Swelling of Irradiated Uranium. Nuclear Energy, 7:88-96, 1958.

[14] T. Ogata and T. Yokoo. Devlopment and Validation of ALFUS: An Irradiation Behavior Analysis Code for Metallic Fast Reactor Fuels. Journal of Nuclear Technology, 128(1):113-123, 1999.

[15] A. Karahan and J. Buongiorno. A new code for predicting the thermo-mechanical and irradiation behavior of metallic fuels in sodium fast reactors. Journal of Nuclear Materials, 396:283-293, 2010.

[16] C Matthews and C Unal. Unpublished work. 2015.

[17] M. C. Billone, Y. Y. Liu, E. E. Gruber, T. H. Hughes, and J. M. Kramer. Status of Fuel Element Modeling Codes for Metallic Fuels. In Proceedings American Nuclear Society Internaionl Conference on Reliable Fuels for Liquid Metal Reactors, Tucson, Arizona, September 7-11 1968.

[18] Ho Jin Ryu, A. M. Yacout, Yeon Soo Kim, and G. L. Hofman. Review of HT9 Cladding Creep Correlations for Advanced Liquid Metal Fast Reactors. In Transactions of the American Nuclear Society, volume 94, pages 797-798. ANS, 2006.

[19] R.A. Leibowitz, L.and Blomquist. Thermal conductivity and thermal expansion of stainless steelsD 9 and HT 9. International Journal of Thermophysics, 9(5):873-883, 1988.

[20] N. Yamanouchi, M. Tamura, H. Hayakawa, and T. Kondo. Accumulation of engineering data for practical use of reduced activation ferritic steel: $8 \% \mathrm{Cr}-2 \% \mathrm{~W}-0.2 \% \mathrm{~V}-0.04 \% \mathrm{Ta}-\mathrm{Fe}$. Journal of Nuclear Materials, 191-194:822-826, 1992.

[21] Richard N Lyon. Liquid metal heat transfer coefficients. Chem. Eng. Prog., 47:75-79, 1951.

[22] VI Subbotin, AK Papovyants, PL Kirillov, and NN Ivanovskii. A study of heat transfer to molten sodium in tubes. Soviet Atomic Energy, 13(4):991-994, 1963.

[23] T. H. Bauer, W. R. Robinson, J. W. Holland, E. A. Rhodes, and A. E. Wright. First overpower tests of metallic IFR fuel in TREAT: Data and analysis from tests M5, M6, and M7. Technical Report ANL-IFR-124, Argonne National Laboratory, 1989.

[24] G. L. Beausoleil, B. J. Curnutt, and G. L. Povirk. A revised capsule design for the accelerated testing of advanced reactor fuels. Technical Report INL/EXT-18-45933, Idaho National Laboratory, 2018. 